\title{
Global molecular analyses of methane metabolism in methanotrophic alphaproteobacterium, Methylosinus trichosporium OB3b. Part I: transcriptomic study
}

\author{
Janet B. Matsen ${ }^{1}$, Song Yang ${ }^{1}$, Lisa Y. Stein ${ }^{2}$, David Beck ${ }^{1,3}$ and Marina G. Kalyuzhnaya ${ }^{4}$ \\ 1 Department of Chemical Engineering, University of Washington, Seattle, WA, USA \\ ${ }^{2}$ Department of Biological Sciences, University of Alberta, Edmonton, AB, Canada \\ ${ }^{3}$ eScience Institute, University of Washington, Seattle, WA, USA \\ ${ }^{4}$ Department of Microbiology, University of Washington, Seattle, WA, USA
}

Edited by:

Amy V. Callaghan, University of Oklahoma, USA

\section{Reviewed by:}

Svetlana N. Dedysh, Russian

Academy of Sciences, Russia

Jeremy Semrau, The University of

Michigan, USA

*Correspondence:

Marina G. Kalyuzhnaya, Department of Microbiology, University of

Washington, Benjamin Hall IRB RM

455, 616 NE Northlake Place, Seattle,

WA 98105, USA.

e-mail:mkalyuzh@uw.edu
Methane utilizing bacteria (methanotrophs) are important in both environmental and biotechnological applications, due to their ability to convert methane to multicarbon compounds. However, systems-level studies of methane metabolism have not been carried out in methanotrophs. In this work we have integrated genomic and transcriptomic information to provide an overview of central metabolic pathways for methane utilization in Methylosinus trichosporium OB3b, a model alphaproteobacterial methanotroph. Particulate methane monooxygenase, PQQ-dependent methanol dehydrogenase, the $\mathrm{H}_{4} \mathrm{MPT}$-pathway, and NAD-dependent formate dehydrogenase are involved in methane oxidation to $\mathrm{CO}_{2}$. All genes essential for operation of the serine cycle, the ethylmalonyl-CoA (EMC) pathway, and the citric acid (TCA) cycle were expressed. PEP-pyruvate-oxaloacetate interconversions may have a function in regulation and balancing carbon between the serine cycle and the EMC pathway. A set of transaminases may contribute to carbon partitioning between the pathways. Metabolic pathways for acquisition and/or assimilation of nitrogen and iron are discussed.

Keywords: methanotrophic proteobacteria, serine cycle, ethylmalonyl-CoA pathway in methanotrophs, TCA, gene expression

\section{INTRODUCTION}

Aerobic methanotrophic bacteria (methanotrophs) are a highly specialized group of microbes utilizing methane as a sole source of carbon and energy (Hanson and Hanson, 1996; Murrell and Jetten, 2009). As the recognition of methane's impact on global climate change increases, a multitude of research activities have been directed toward understanding the natural mechanisms for reducing methane emissions, including consumption by methanotrophs. The number of described microbial species capable of methane oxidation has recently expanded dramatically. A number of novel methanotrophic phyla have been isolated and described in the past few years, including new members of the Alphaand Gammaproteobacteria, and Verrucomicrobia (Trotsenko and Murrell, 2008; Chistoserdova et al., 2009; Murrell and Jetten, 2009). Several genomes of methanotrophic bacteria have been sequenced opening new dimensions in characterization of methane metabolism (Ward et al., 2004; Dunfield et al., 2007; Hou et al., 2008; Chen et al., 2010; Stein et al., 2010, 2011; Dam et al., 2012b). Initial genome-based reconstructions of methane metabolism in methanotrophic proteobacteria and Verrucomicrobia have been performed (Ward et al., 2004; Kelly et al., 2005; Hou et al., 2008; Khadem et al., 2011).

Methylosinus trichosporium OB3b, an obligate alphaproteobacterial methanotroph, has served as a model system for years (first described in Whittenbury et al., 1970). Research on both fundamental and biotechnological aspects of methanotrophy in M. trichosporium OB3b has been carried out with applications involving cometabolism of contaminants (Oldenhuis et al., 1991; EPA, 1993; Fitch et al., 1996), epoxidation of propene (Hou et al., 1979), and synthesis of polyhydroxybutyrate (PHB) (Williams, 1988; Doronina et al., 2008). M. trichosporium OB3b possesses two systems for methane oxidation, a particulate methane monooxygenase (pMMO), expressed under high biomass/copper ratios, and a soluble methane monooxygenase (sMMO) which is expressed at low copper conditions (Hakemian and Rosenzweig, 2007; Semrau et al., 2010). It has been shown that the strain is capable of fixing nitrogen (Oakley and Murrell, 1988; Auman et al., 2001). Although significant progress has been made in the understanding of primary methane and methanol oxidation pathways in this model bacterium, little work has been carried out on carbon assimilation by $M$. trichosporium OB3b. The reconstruction of the core metabolic pathways for alphaproteobacterial methanotrophs has been primarily based on a restricted set of enzymatic studies and extrapolations relying on similarity to non-methane utilizing methylotrophs (Lawrence and Quayle, 1970; Strom et al., 1974). A draft genome of M. trichosporium OB3b has recently been generated (Stein et al., 2010). This genetic blueprint provides an essential background for revisiting the established model of methanotrophy in Alphaproteobacteria using modern system-level approaches. For this research, we 
integrated heterogeneous multi-scale genomic, transcriptomic, and metabolomic data to redefine the metabolic framework of $\mathrm{C}_{1}$-utilization in $M$. trichosporium $\mathrm{OB} 3 \mathrm{~b}$ grown in batch culture under copper, oxygen, and iron sufficiency on methane and nitrate as the sources of carbon and nitrogen, respectively. In this part of our work we present transcriptomic-based analysis of the methanotrophic metabolic network. Metabolomic and ${ }^{13} \mathrm{C}$-labeling studies are presented in a follow-up paper (Yang et al., 2013).

\section{RESULTS AND DISCUSSION GENE EXPRESSION STUDIES}

Gene expression studies were carried out with $M$. trichosporium OB3b cultures grown on methane at $\mathrm{N}(10 \mathrm{mM}), \mathrm{Cu}(9 \mu \mathrm{M})$, and Fe $(9 \mu \mathrm{M})$ sufficiency conditions. The maximum specific growth rate of $M$. trichosporium $\mathrm{OB} 3 \mathrm{~b}$ in shake flasks during the exponential growth phase was $\mu=0.038 \pm 0.004 \mathrm{~h}^{-1}$. The methane consumption rate during the period of maximum growth rate was $8.95 \mathrm{mmol}^{\circ} \mathrm{CH}_{4} \mathrm{~h}^{-1}$ L culture $^{-1}\left(\mathrm{OD}_{600}=1\right)$.

All experiments were performed with at least two biological replicates. RNA samples were prepared as described in the Section "Materials and Methods." Illumina sequencing for two biological replicates (BR1 and BR2) returned 28 and 29 million 36-bp reads. The Burrows-Wheeler Aligner (BWA, Li and Durbin, 2009) aligned $98 \%$ of the reads to the M. trichosporium OB3b genome annotated by $\mathrm{MaGE}^{1}$ using the default parameters for small genomes. Reads per kilobase of coding sequence per million (reads) mapped (RPKM) (Mortazavi et al., 2008) was calculated to compare gene expression within and across replicates, and no further normalization (other than RPKM) was applied. The samples were in good agreement with each other, with per gene coding sequence RPKM correlations of 0.959 and 0.989 for the Pearson and Spearman correlations, respectively. In total, 4,762 of 4,812 ORFs (CDS, tRNA, and rRNA predicted from the draft genome) were detected. Based on relative expression, genes (omitting rRNAs) could be grouped into six major expression categories (Table 1): very high $(\mathrm{RPKM} \geq 15,000)$, high $(\mathrm{RPKM} \geq 1,500)$, moderate $(1,500>\mathrm{RPKM} \geq 500)$, modest $(500>\mathrm{RPKM} \geq 250)$, low $(250>\mathrm{RPKM} \geq 150)$ very low $(150>\mathrm{RPKM} \geq 15)$, and not expressed $(\mathrm{RPKM}<15)$. The majority of genes fell into low/very low expression categories (74\%). About 14\% of genes displayed moderate/modest expression and only a small fraction of the genome showed very high/high expression (2.7\%).

In order to determine whether the draft genome of the strain is missing some functional genes, we performed de novo assembly of the transcriptome. Using this approach, a total of 173 genes that are not present in the genome sequence, but have homologs in the non-redundant database were detected. Among those are key subunits of succinate dehydrogenase ( $s d h A B C D)$, 2-oxoglutarate dehydrogenase (E2), and nitric oxide reductase (norB) (Table S1 in Supplementary Material). The de novo transcriptome assembly provides additional information for highly expressed genes and it was used for verification of some metabolic functions that were predicted by enzymatic studies but were not detected in the draft genome assembly (see below).

\footnotetext{
${ }^{1}$ https://www.genoscope.cns.fr/agc/microscope/mage
}

Table 1 | Classification of gene expression level based on replicate averaged RPKMs.

\begin{tabular}{lccl}
\hline $\begin{array}{l}\text { Description of } \\
\text { expression level }\end{array}$ & RPKM range & \% of ORFs & Number of ORFs \\
\hline Very high & $>15,000$ & 0.23 & 11 \\
High & $1,500-15,000$ & 2.49 & 120 \\
Moderate & $500-1,500$ & 5.30 & 255 \\
Modest & $250-500$ & 8.61 & 414 \\
Low & $50-250$ & 40.41 & 1,944 \\
Very low & $15-50$ & 23.70 & 1,140 \\
Not expressed & $<15$ & 19.27 & 927 \\
\end{tabular}

In addition, the reads obtained from RNA-seq were aligned to the reference genome in order to identify transcription boundaries and transcription start sites for the most highly expressed genes, including the $p m o C A B$ operons, mxaFJGI operon, fae $1, p q q A$, and key genes of the serine cycle (Table S2 in Supplementary Material, see description below). Gene expression data were used to reconstruct central metabolic pathways in M. trichosporium OB3b (Table 2; Figure 1; Table S2 in Supplementary Material). Core functions are described below.

\section{$C_{1}$-OXIDATION: METHANE-TO-METHANOL}

It has been previously demonstrated that $M$. trichosporium $\mathrm{OB} 3 \mathrm{~b}$ possesses two types of methane oxidation enzymes: pMMO and sMMO. The expression of the enzymes is determined by copper availability; sMMO is dominant in copper-limited environments while pMMO dominates under copper sufficiency (Hakemian and Rosenzweig, 2007; Semrau et al., 2010). Structures of both enzymes are available (Elango et al., 1997; Hakemian et al., 2008). In this study, M. trichosporium OB3b was grown at a copper concentration that has been shown to be sufficient to suppress the expression of sMMO (Park et al., 1991; Phelps et al., 1992; Nielsen et al., 1997; Lloyd et al., 1999; Murrell et al., 2000). Indeed, virtually no expression of the sMMO gene cluster (mmoXYBZC) was observed. In contrast, the $p m o C A B$ genes were the most highly expressed in the transcriptome, representing about $14 \%$ of all reads mapped to the coding regions (Table 2 ). It has previously been shown that $\mathrm{PMMO}$ in $M$. trichosporium OB3b is encoded by two copies of the $p m o C A B$ operon that appear to be identical (Gilbert et al., 2000). The current genome assembly failed to resolve these closely related duplicated regions. The $p m o C A B$ genes were found within one relatively short contig, which includes $320 \mathrm{bp}$ upstream from $p m o C$, and about $66 \mathrm{bp}$ downstream from $p m o B$. It is possible that in the genome assembly, the pmo contig represents only those parts of the duplicated regions that are highly similar. Thus, it was not possible to determine relative expression of the two operons with the transcriptomic data.

Previous attempts to identify transcriptional starts of the pmo$C A B$ operons in $M$. trichosporium OB3b using a conventional primer extension approach were not successful (Gilbert et al., 2000). The RNA-seq data were used for identification of transcriptional starts for the $p m o C A B$ operons. Because the published METTOv1 genome did not contain a complete $p m o C A B$ cluster, a separate alignment run was performed using a previously 
Table 2 | Gene expression profile in methane-grown cells of $M$. trichosporium OB3b.

\begin{tabular}{|c|c|c|c|c|}
\hline Gene ID & Predicted function & Gene & Replicate 1 & Replicate 2 \\
\hline METTOv1_1270003 & Particulate methane monooxygenase subunit C & pmoC & 123026 & 127241 \\
\hline METTOv1_1270001 & Particulate methane monooxygenase subunit B & pmoB & 27371 & 22917 \\
\hline METTOv1_310040 & Particulate methane monooxygenase subunit C2 & pmoC2 & 532 & 492 \\
\hline METTOv1_50081 & Soluble methane monooxygenase alpha subunit & $\operatorname{mmoX}$ & 9 & 8 \\
\hline METTOv1_50084 & Soluble methane monooxygenase gamma subunit & mmoZ & 20 & 19 \\
\hline METTOv1_240014 & POQ-dependent methanol dehydrogenase & $m x a F$ & 15313 & 13760 \\
\hline METTOv1_240011 & PQQ-dependent methanol dehydrogenase & mxal & 24552 & 28474 \\
\hline METTOv1_240012 & Cytochrome $c$ class I & $m \times a G$ & 5712 & 6117 \\
\hline METTOv1_240013 & Extracellular solute-binding protein family 3 & mxaJ & 1942 & 1838 \\
\hline METTOv1_240005 & von Willebrand factor type $A$, involved in methanol oxidation & $m x a L$ & 191 & 201 \\
\hline METTOv1_240006 & Protein of unknown function, involved in methanol oxidation & $m x a K$ & 124 & 132 \\
\hline METTOv1_240007 & von Willebrand factor type $A$, involved in methanol oxidation & $m \times a C$ & 144 & 141 \\
\hline METTOv1_240008 & MxaA protein, involved in methanol oxidation & $m \times a A$ & 137 & 127 \\
\hline METTOv1_240009 & MxaS protein, involved in methanol oxidation & $m x a S$ & 202 & 167 \\
\hline METTOv1_240010 & ATPase, involved in methanol oxidation & $m x a R$ & 563 & 538 \\
\hline METTOv1_110056 & Coenzyme $\mathrm{PQQ}$ biosynthesis protein $\mathrm{A}$ & $p q q A$ & 11857 & 13927 \\
\hline METTOv1_160001 & Coenzyme $\mathrm{PQQ}$ biosynthesis protein $\mathrm{E}$ & pqqE & 166 & 161 \\
\hline METTOv1_160002 & Coenzyme $\mathrm{PQO}$ biosynthesis protein $\mathrm{PqqC} / \mathrm{D}$ & $p q q C / D$ & 372 & 344 \\
\hline METTOv1_160003 & Coenzyme $\mathrm{PQQ}$ biosynthesis protein $\mathrm{B}$ & $p q q B$ & 306 & 313 \\
\hline METTOv1_20046 & Coenzyme $\mathrm{PQQ}$ biosynthesis protein $\mathrm{F}$ & $p q q F$ & 183 & 185 \\
\hline METTOv1_40012 & Tetrahydromethanopterin-linked C1 transfer pathway protein, Orf7 & orf7 & 73 & 72 \\
\hline METTOv1_40013 & Formaldehyde activating enzyme & fae1 & 24353 & 24787 \\
\hline METTOv1_40014 & Formaldehyde activating enzyme & fae $1-2$ & 4024 & 3676 \\
\hline METTOv1_840013 & Formaldehyde activating enzyme homolog & fae2 & 535 & 581 \\
\hline METTOv1_40015 & Tetrahydromethanopterin-linked C1 transfer pathway protein & orf17 & 38 & 45 \\
\hline METTOv1_110058 & Tetrahydromethanopterin formyltransferase, subunit C & fhcC & 535 & 453 \\
\hline METTOv1_110059 & Tetrahydromethanopterin formyltransferase, subunit D & $f h c D$ & 496 & 470 \\
\hline METTOv1_110060 & Tetrahydromethanopterin formyltransferase, subunit $A$ & fhcA & 591 & 546 \\
\hline METTOv1_110061 & Tetrahydromethanopterin formyltransferase, subunit B & $f h c B$ & 620 & 570 \\
\hline METTOv1_560001 & Tetrahydromethanopterin -linked C1 transfer pathway protein & orf9 & 172 & 167 \\
\hline METTOv1_560002 & Methylenetetrahydrofolate dehydrogenase (NAD) & $m t d B$ & 688 & 607 \\
\hline METTOv1_440045 & Ribofuranosylaminobenzene 5'-phosphate synthase & $m p t G$ & 94 & 80 \\
\hline \multicolumn{5}{|c|}{ FORMATE OXIDATION } \\
\hline METTOv1_630016 & Transcriptional regulator, LysR family & $f d s R$ & 52 & 39 \\
\hline METTOv1_630017 & NAD-linked formate dehydrogenase, subunit G & $f d s G$ & 672 & 608 \\
\hline METTOv1_630018 & NAD-linked formate dehydrogenase, subunit B & $f d s B$ & 585 & 531 \\
\hline METTOv1_630019 & NAD-linked formate dehydrogenase, subunit A & $f d s A$ & 593 & 554 \\
\hline METTOv1_370001 & Formate dehydrogenase family accessory protein & $f d s C$ & 210 & 199 \\
\hline
\end{tabular}


Table 2 | Continued

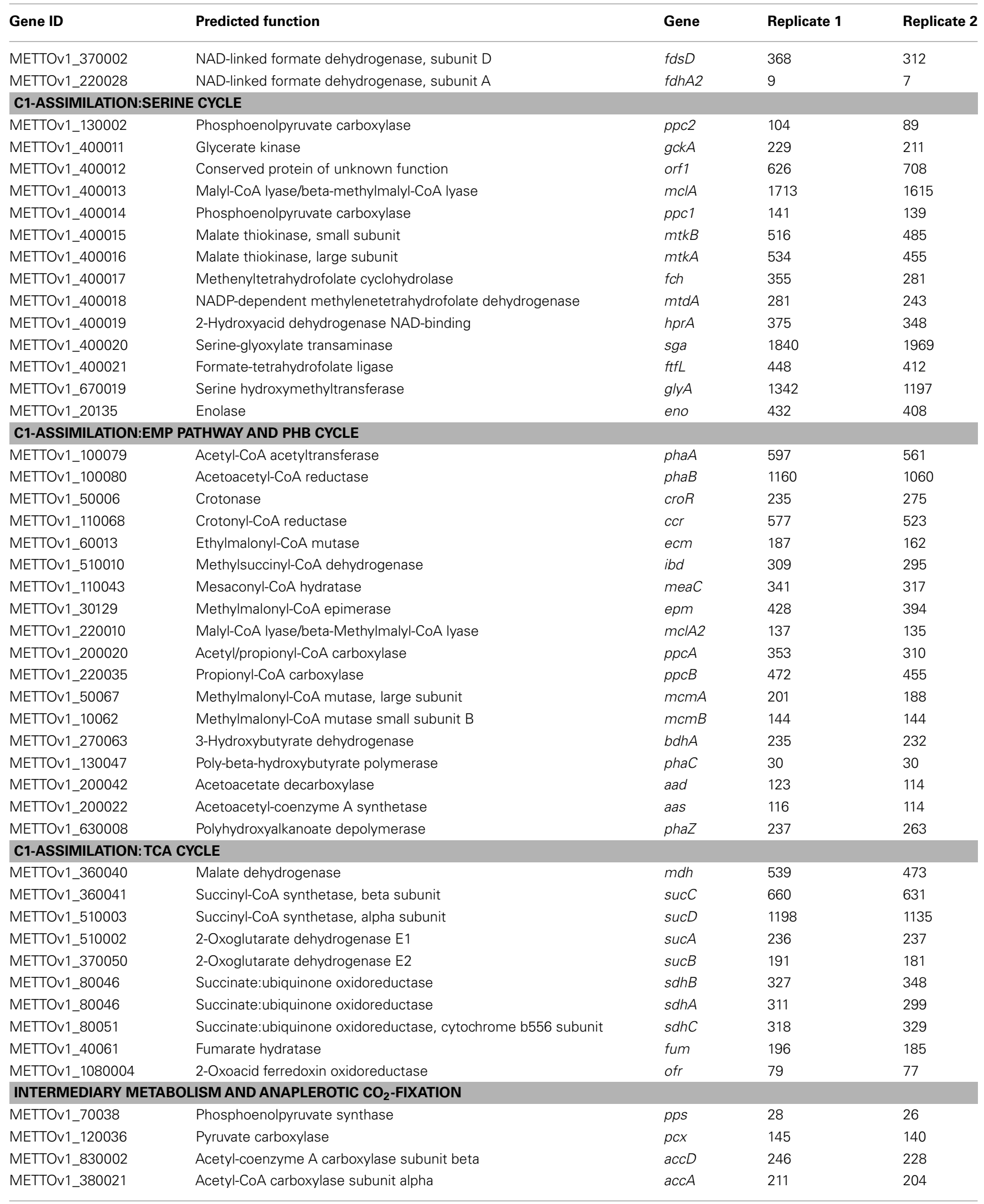


Table 2 | Continued

\begin{tabular}{|c|c|c|c|c|}
\hline Gene ID & Predicted function & Gene & Replicate 1 & Replicate 2 \\
\hline METTOv1_150014 & Pyruvate kinase & pyk1 & 245 & 224 \\
\hline METTOv1_340041 & Pyruvate dehydrogenase subunit beta & $p d h B$ & 160 & 158 \\
\hline METTOv1_340042 & Pyruvate dehydrogenase & $p d h C$ & 101 & 106 \\
\hline METTOv1_680013 & Phosphoglycerate mutase & gpmA & 136 & 135 \\
\hline METTOv1_100061 & Phosphoglycerate mutase (modular protein) & pgm & 101 & 99 \\
\hline METTOv1_10180 & Phosphoglycerate mutase (modular protein) & pgm & 72 & 65 \\
\hline METTOv1_280049 & Phosphoglycerate kinase & $p g k$ & 199 & 208 \\
\hline METTOv1_280047 & Glyceraldehyde-3-phosphate dehydrogenase & gpd & 391 & 407 \\
\hline METTOv1_220030 & 6-Phosphofructokinase & pfk & 243 & 239 \\
\hline METTOv1_200031 & Fructose 1,6-bisphosphatase II & $g / p$ & 68 & 56 \\
\hline METTOv1_550029 & Glucose-6-phosphate isomerase & pgi & 88 & 84 \\
\hline METTOv1_620022 & Ribulose-phosphate 3-epimerase & rpe & 51 & 53 \\
\hline \multicolumn{5}{|c|}{ NITROGEN, Cu, Fe METABOLISM } \\
\hline METTOv1_310019 & Nitrate transporter component & nrtA & 151 & 154 \\
\hline METTOv1_310020 & Nitrite reductase $(\mathrm{NAD}(\mathrm{P}) \mathrm{H})$, large subunit & nas $B$ & 1762 & 1562 \\
\hline METTOv1_310021 & Nitrite reductase $(N A D(P) H)$, small subunit & nasD & 726 & 610 \\
\hline METTOv1_310022 & Nitrate reductase, large subunit & nas $A$ & 646 & 597 \\
\hline METTOv1_130049 & Ammonium transporter & $a m t B$ & 2029 & 1766 \\
\hline METTOv1_300058 & Glutamate synthase large subunit (NADPH/GOGAT) & $g / t B$ & 199 & 183 \\
\hline METTOv1_560023 & Cytochrome $c^{\prime}$-alpha & cycA & 336 & 370 \\
\hline METTOv1_230076 & Putative oxygenase & & 6 & 8 \\
\hline METTOv1_230077 & Hydroxylamine reductase & hcp & 21 & 16 \\
\hline METTOv1_230078 & Putative transcriptional regulator & $n s r R$ & 38 & 35 \\
\hline METTOv1_730005 & Putative FecR iron sensor protein & $f e c R$ & 48 & 58 \\
\hline METTOv1_730006 & Putative TonB-dependent receptor protein & $\operatorname{ton} B$ & 382 & 383 \\
\hline METTOv1_CDS4222756D & Methanobactin precursor & $M b$ & 1439 & 2177 \\
\hline METTOv1_730007 & Putative lyase & & 306 & 384 \\
\hline METTOv1_730008 & Conserved protein of unknown function & $h p$ & 170 & 175 \\
\hline METTOv1_730009 & Conserved protein of unknown function & $h p$ & 116 & 143 \\
\hline METTOv1_660011 & I-Ornithine 5-monooxygenase & $p v d A 1$ & 1410 & 1450 \\
\hline METTOv1_760004 & Putative hydroxy-l-ornithine formylase & $p v d F$ & 2255 & 2676 \\
\hline METTOv1_760006 & I-Ornithine 5-monooxygenase & $p v d A 2$ & 979 & 1116 \\
\hline METTOv1_760007 & Diaminobutyrate-2-oxoglutarate aminotransferase & $p v d H$ & 720 & 770 \\
\hline METTOv1_760008 & Sigma-24 (Fecl-like) & pvdS & 1260 & 1522 \\
\hline METTOv1_760009 & Putative pyoverdine $A B C$ export system, permease & $p v d E$ & 532 & 500 \\
\hline METTOv1_760010 & TonB-dependent siderophore receptor & $f p v A$ & 2197 & 2174 \\
\hline METTOv1_760011 & FecR-like protein & $f e c R$ & 330 & 321 \\
\hline
\end{tabular}


Table 2 | Continued

\begin{tabular}{|c|c|c|c|c|}
\hline Gene ID & Predicted function & Gene & Replicate 1 & Replicate 2 \\
\hline METTOv1_760012 & Fecl-family sigma factor & fecl & 922 & 951 \\
\hline METTOv1_870003 & Ferribactin synthase & $p v d L$ & 433 & 441 \\
\hline METTOv1_870004 & Pyoverdine biosynthesis regulatory protein-TauD/TfdA family protein & & 932 & 1039 \\
\hline METTOv1_870005 & Pyoverdine synthetase, thioesterase component & $p v d G$ & 1542 & 1473 \\
\hline METTOv1_870006 & Integral components of bacterial non-ribosomal peptide synthetases & $\mathrm{MbtH}$ & 4176 & 5481 \\
\hline METTOv1_1220001 & Putative pyoverdine sidechain peptide synthetase IV, d-Asp-I-Ser component & $p v d l / J$ & 480 & 564 \\
\hline METTOv1_1220002 & Putative non-ribosomal peptide synthase & $p v d J / D$ & 379 & 396 \\
\hline
\end{tabular}

Values represent reads per kilobase of coding sequence per million (reads) mapped (RPKM).

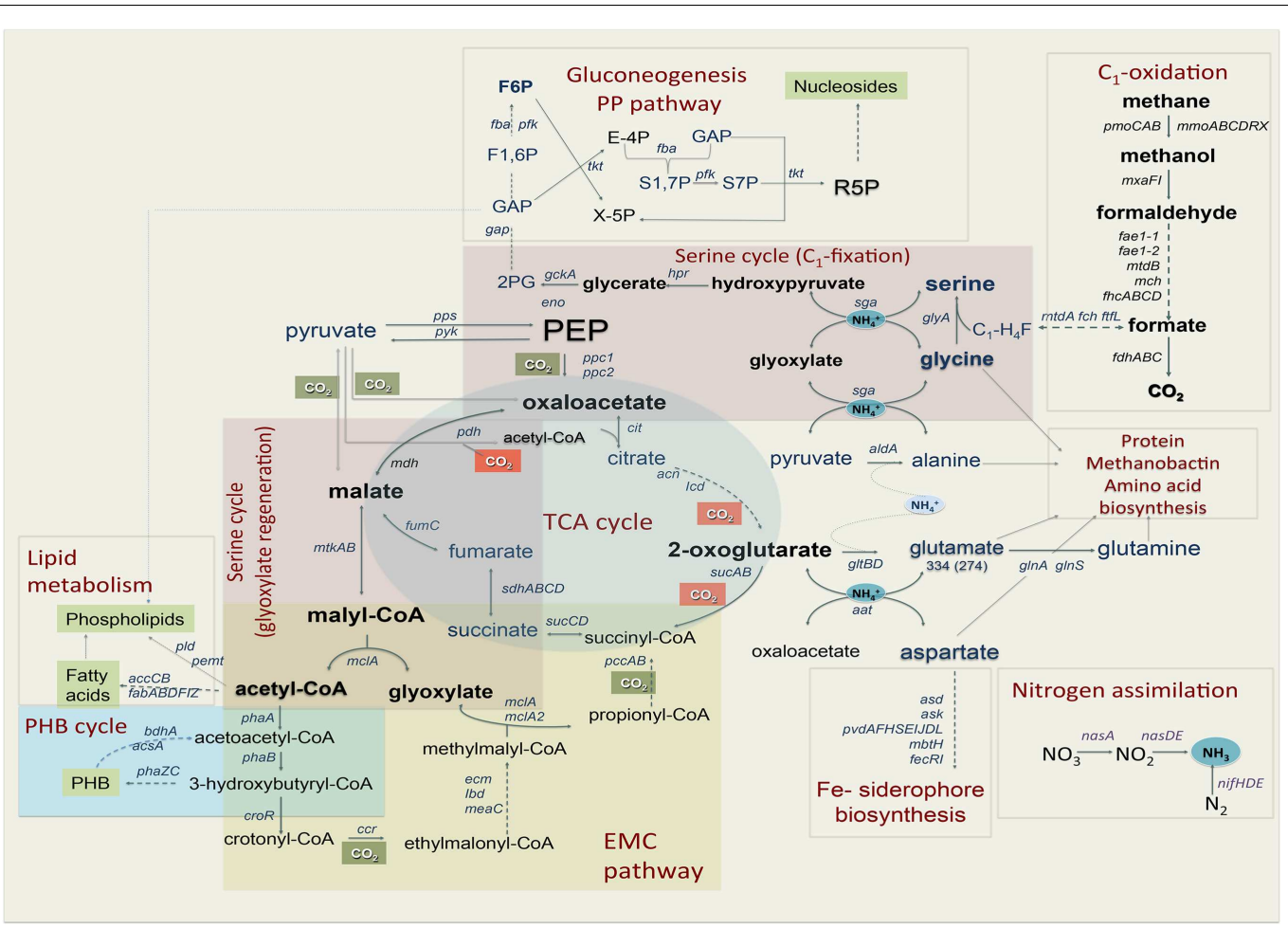

FIGURE 1 | Central metabolism of Methylosinus trichosporium OB3b grown on methane as sole source of energy and carbon as deduced from the genome sequences and transcriptomic studies. Font size of the gene name indicates the expression level.

published sequence as the scaffold (Holmes et al., 1995). For this sequence, two possible transcriptional start sites were identified. It is not known whether these reflect the same start sites of both operons, different start sites for each, or expression of only one operon with two start sites. The position $-274 n t$ (A) from the translational start of the $p m o C$ gene was predicted as the most prominent start of transcription of the operon (Figure S1 in Supplementary Material). Putative $\sigma^{70}$-like -10 and -35 regions could be identified upstream of the predicted start (Table S3 in Supplementary Material). The structure of the putative promoter region from $M$. trichosporium OB3b shows significant similarity to a pmoCAB promoter region previously identified in Methylocystis sp. M (Gilbert et al., 2000). Another potential transcriptional start is at position -324 from the translational start of the $p m o C$ gene. It should be noted that the region between the two predicted start sites was also covered with relatively high count (region between -324 and $-274 n t$ with respect to the translational start of $p m o C$ ). No putative promoter sequences were found upstream of position 324 .

The genome predicts an additional copy of the pmoC gene by itself ( $p m o C 2$, METTOv1_310040), which can be distinguished from the other $p m o C$ genes in the transcriptomics data due to sequence divergence. It has previously been demonstrated that additional copies of $p m o C$ are essential for methanotrophic growth in other strains (Stolyar et al., 1999; Dam et al., 2012a). It has also been shown that the homologous amoC (additional lone copy of amoC in ammonia-oxidizing bacterium Nitrosomonas europaea) plays role in cell recovery from ammonium starvation (Berube and Stahl, 2012). However the functional role of PmoC is 
not known. The relative expression of pmoC2 was approximately 450 -fold less than the expression of the two pmoC genes from the pmo-operons (Table 2). Low relative expression of the $p m o C$ homolog may suggest a role in regulation or sensing rather than catalytic activity.

\section{$C_{1}$-OXIDATION: METHANOL-TO-FORMALDEHYDE}

The product of methane oxidation (i.e., methanol) is converted to formaldehyde by a PQQ-dependent methanol dehydrogenase (MDH) (Anthony, 1982, 2002; Yamada et al., 1991; Anthony et al., 1994). The enzyme has been previously purified from $M$. trichosporium $\mathrm{OB} 3 \mathrm{~b}$ and well characterized (Yamada et al., 1991). $\mathrm{MDH}$ is a hetero-tetrameric enzyme encoded by $m x a F$ and $m x a I$. The activity of the enzyme in vivo requires cytochrome $\mathrm{c}_{\mathrm{L}}(m x a G)$ and a number of chaperones, regulators, and enzymes, including genes required for $\mathrm{Ca}^{2+}$ insertion (Anthony et al., 1994; Anthony, 2002). Most of the genes essential for this methanol conversion step in M. trichosporium $\mathrm{OB} 3 \mathrm{~b}$ are organized in one large operon in an order similar to that found in other methylotrophs (Figure S2A in Supplementary Material). The first four genes of the operon (mxaFJGI), encoding the two subunits of the MDH, the associated cytochrome, and a gene of unknown function ( $m x a J)$ were detected at relatively high RPKM counts. The relative expression of genes downstream from mxaI, including those for chaperones, regulators, and $\mathrm{Ca}^{2+}$ insertion functions drops by 10 - to 50 -fold (Table 2). The overall mapping pattern of the mxa-cluster is as follows: mxaFJGI (highly expressed), mxaD (moderate expression), mxaRSACKL, mxaB (low expression), and mxaY (very low expression). It remains to be elucidated if the mxaRSACKL transcripts arise from the same start as $m x a F$ and are attenuated by some transcriptional or post-transcriptional mechanism, or whether separate, lower expression promoter(s) is/are present. Orientations and/or the expression patterns of $m x a D, m x a B$, and $m x a Y$, suggest that they are not part of the major mxaF-operon (Figure S2A in Supplementary Material) and most likely have independent regulatory/promoter regions. According to RNA-seq mapping data, a putative transcriptional start of the mxaFJGI operon is predicted at position -164 from the predicted translational start (Figure S3 in Supplementary Material). Just upstream from the predicted transcriptional start, putative $\sigma^{70}$-like -10 and -35 sequences were identified (Table S3 in Supplementary Material).

The genome of $M$. trichosporium $\mathrm{OB} 3 \mathrm{~b}$ contains the following three homologs of the large subunit of the $\mathrm{MDH}$ : $x \circ \mathrm{xF} 1, x \circ \mathrm{xF} 2$, and $x o x F 3$. Relative expression of all $x o x F$-homologs is very low. The most highly expressed $x o x$-homolog ( $x o x F 1)$ showed only about $2 \%$ of the mxaF expression. The function of the $x o x$-gene products has not been studied in M. trichosporium OB3b. In the non-methanotrophic methylotroph Methylobacterium extorquens AM1, it has been shown that $x o x F$ may display methanol-oxidizing activity (Schmidt et al., 2010), and can contribute to the complex regulation of mxa-genes (Skovran et al., 2011). Furthermore, there are suggestions that $x o x F$ may play a role in formaldehyde oxidation (Wilson et al., 2008). The low expression of all xoxF-homologs in M. trichosporium OB3b compared to mxaFI or $\mathrm{H}_{4} \mathrm{MTP}$-linked pathway genes suggests that xox-genes may have no or a minor contribution to methanol oxidation in M. trichosporium OB3b under the tested growth conditions. However, our data do not rule out the possibility that one or more of the xoxF gene products are involved in regulation, either of methanol or formaldehyde oxidation.

Pyrroloquinoline quinone (PQQ) biosynthesis is another function essential for operation of the primary methanol oxidation system (Toyama et al., 1997; Anthony, 2002). A total of six pqq genes appear to be present in the $M$. trichosporium OB3b genome in two clusters: $p q q B C D E$ and $p q q F G$. Moderate expression of both clusters was observed (Table 2). No gene for the small PQQ precursor (PqqA) is predicted in the current version of the genome. Our manual review of the sequences revealed a fragment within the METTOv1_110055 - METTOv1_110057 gene locus (positions 1424678 - 1424755 of current version of the genome) with high sequence identity [83\% nucleic acid (NA) identity and $96 \%$ amino acid (AA) similarity] to the $p q q A$ sequence from Methylobacterium spp (Figures 2A,B). Transcript mapping data indicated that only the $p q q A$-like region of the locus is highly expressed (Figure 2C). The relative expression of the putative PQQ precursor gene is comparable to the high expression of the $m x a F I$ genes. The rest of the genes involved in PQQ biosynthesis showed modest to low expression (Figure S2B in Supplementary Material).

\section{$C_{1}$-OXIDATION: FORMALDEHYDE-TO-FORMATE}

Previous enzymatic studies predict three possible pathways for formaldehyde oxidation: (1) direct oxidation through dye-linked heme-containing formaldehyde dehydrogenase (Patel et al., 1980), (2) $\mathrm{H}_{4}$ folate-, and (3) $\mathrm{H}_{4}$ MTP-mediated $\mathrm{C}_{1}$ transfers (Vorholt et al., 1999; Doronina et al., 2008). Contrary to enzymatic studies, BLAST searches of the draft genome of $M$. trichosporium OB3b did not reveal any obvious system that could be attributed to heme-containing formaldehyde oxidation. Three broadspecificity aldehyde-detoxification systems, including two NADdependent aldehyde dehydrogenases (Aldh-F7 METTOv1_100046 and Aldh, METTOv1_610028) and one aldehyde oxidase (Aor, METTOv1_290006) were predicted in the genome. Two of them, aldh and aor show low expression (Table 2), while aldh-F7 was barely detected in the transcriptome. None of the putative genes identified by de novo transcriptome assembly could be readily attributed to any dye-linked aldehyde dehydrogenases (Schwartz et al., 2004). Thus, even if the enzyme is present in the genome, its expression during growth of the strain on methane must be low.

For years it has been assumed that methylene $\mathrm{H}_{4} \mathrm{~F}$ is formed as a result of the spontaneous (non-enzymatic) condensation of formaldehyde with $\mathrm{H}_{4} \mathrm{~F}$ (Large and Quayle, 1963). It has recently been demonstrated that formate, rather than formaldehyde serves as an entry substrate for assimilation in serine cycle methylotrophs (Crowther et al., 2008). With this metabolic arrangement, the $\mathrm{H}_{4}$ Folate $\mathrm{C}_{1}$ transfer could be considered as a part of the assimilatory network that converts formate into methylene $\mathrm{H}_{4} \mathrm{~F}$. In $M$. trichosporium OB3b genes encoding all three steps of the $\mathrm{H}_{4}$ Folate pathway converting methylene- $\mathrm{H}_{4} \mathrm{~F}$ to formate (formyl- $\mathrm{H}_{4} \mathrm{~F}$ ligase, $\mathrm{ftfL}$, methenyl- $\mathrm{H}_{4} \mathrm{~F}$ cyclohydrolase, $\mathrm{fch}$, and methylene- $\mathrm{H}_{4} \mathrm{~F}$ dehydrogenase $m t d A$ ) were co-localized and co-transcribed with genes encoding the serine cycle enzymes 
A

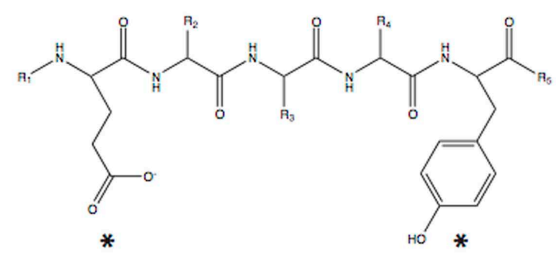

B

Klebsiella pneumoniae - - MWK K P A F I D LR LG LEVT L L I S NR' . . . . Acinetobacter calcoaceticus - MQWT K P A FT D LR I G FEV TMY F E AR - . - . Hyphomicrobium denitrificans MKT WT K P A VR EQ EV GLEVT SY LPAE I D - - Methylobacterium sp. GXF4 - MAWSAPVVSE I CVGMEVT SYE SAE I DT FN Methylobacterium extorquens AM1 - MW S A P V V A E I C V GMEVT SYE SAE I DT FN Methylosinus trichosporium OB3b - MAWT APV I VEV CVGME I T SYE SAE I - - -

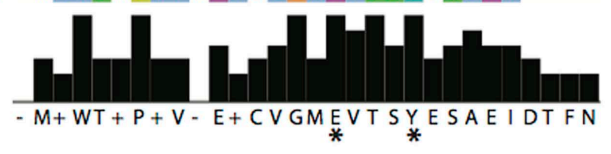

C

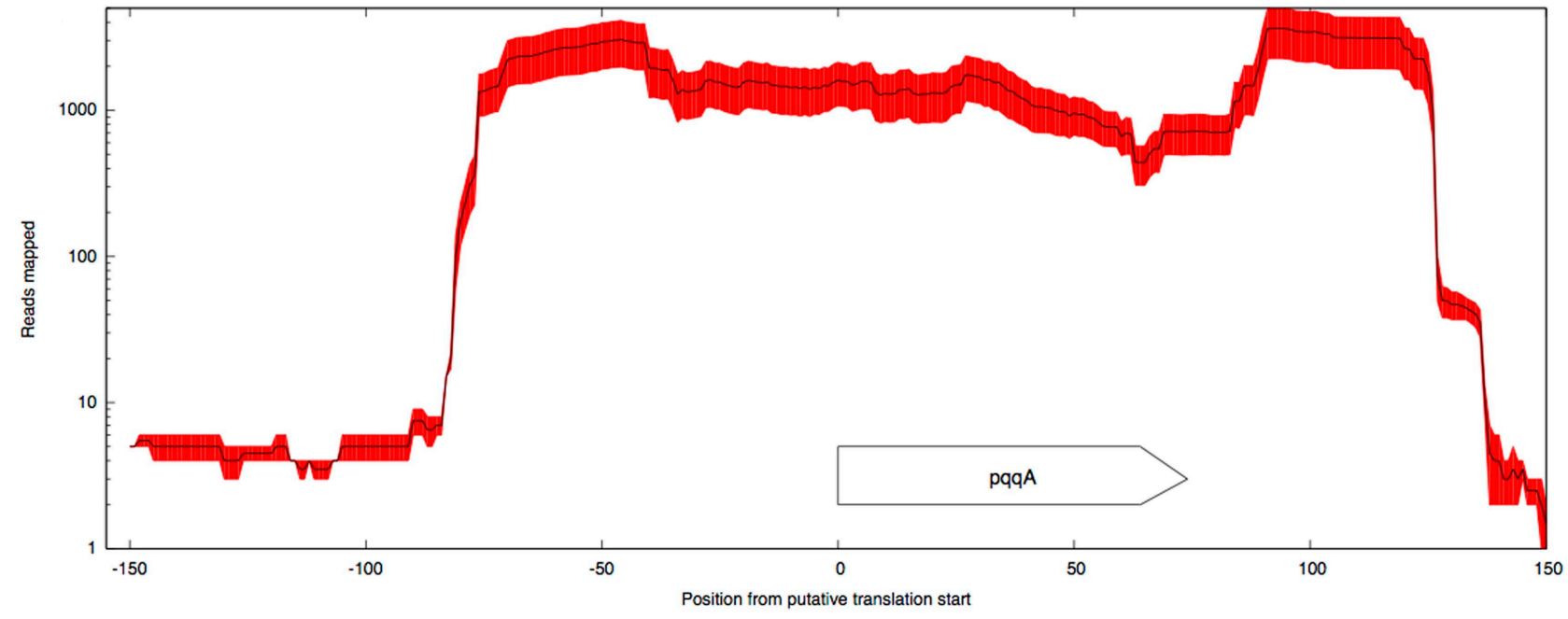

FIGURE 2 | Predicted structure (A) and alignment of the putative pqqA peptide (B) from M. trichosporium OB3b and pqqA peptides from Methylobacterium sp. GXF4, M. extorquens AM1, Hyphomicrobium denitrificans ATCC51888, K. pneumoniae, and A. calcoaceticus. (C) Mapping.

(Figure S4 in Supplementary Material). While the assimilatory function of the pathway is more apparent, it is still possible that key enzymes of the pathway contribute to formaldehyde oxidation in M. trichosporium OB3b.

The tetrahydromethanopterin $\left(\mathrm{H}_{4} \mathrm{MTP}\right)$ pathway was proposed to be the key pathway for formaldehyde oxidation/detoxification in alphaproteobacterial methylotrophs (Chistoserdova et al., 1998). It was speculated that this pathway contributes to formaldehyde oxidation in methane utilizing proteobacteria (Vorholt et al., 1999). Nineteen genes encoding enzymes and genes for tetrahydromethanopterin biosynthesis were identified in the $M$. trichosporium OB3b genome. These genes were not clustered together in the genome, but formed five different gene islands: (1) mch-orf5-orf7-fae1/1-fae1/2-orf17 (Figure S2C in Supplementary Material); (2) orf19-orf20-afpA-orf21-orf22; (3) fhcCDAB; (4) orf9-mtdB; and (5) pcbD-mptG. No homologs of orfY, $d m r A$, and $p a b B$ genes, which are commonly associated with tetrahydromethanopterin biosynthesis in methylotrophs (Caccamo et al., 2004; Rasche et al., 2004; Chistoserdova et al., 2005; Kalyuzhnaya et al., 2005), were found in the genome or detected in transcriptome.

Formaldehyde activating enzyme (FAE) is the first enzyme of the $\mathrm{H}_{4} \mathrm{MTP}$-pathway, which has been shown to catalyze the condensation of formaldehyde and $\mathrm{H}_{4} \mathrm{MPT}$ to form methylene- $\mathrm{H}_{4}$ MPT (Vorholt et al., 2000). The draft genome of
M. trichosporium OB3b predicts three homologs of Fae; two of them (fael/1 and fael/2) share a high degree of identity (NA $82.2 \%$ ) and are co-localized in the genome (Figure S2C in Supplementary Material). Though both fae genes are clustered with four other genes involved in the $\mathrm{H}_{4}$ MTP-pathway, they are expressed in dramatically different patterns. The abundance of fae1-1 transcripts was almost 40-fold higher than the abundance of any other gene in the cluster, except fae1-2 (Table 2; Figure S2C in Supplementary Material). The relative abundance of the second homolog (fae1-2) was one fifth of that observed for fae 1-1, and fae1-2 was the second highest expressed gene in the pathway. Mapping data indicate that fae 1-1 and fae1-2 are most likely co-transcribed (Figure S5 in Supplementary Material). RNA-Seq mapping data suggest two putative transcriptional starts at the positions -215 (with $\sigma^{70}$-like -10 and -35 sequences upstream) and -105 (with a conserved "AATGGTTG" sequence in the -35 region) upstream from the fae 1-1 translational start (Figure S5 in Supplementary Material; Table S3 in Supplementary Material).

The third homolog of Fae (fae2) demonstrates moderate expression. The rest of the genes encoding key enzymes of the pathway ( $m t d B$, methylene- $\mathrm{H}_{4} \mathrm{MPT}$ dehydrogenase; $m c h$, methenyl$\mathrm{H}_{4}$ MPT cyclohydrolase; fhcABCD, formyltransferase/hydrolase) have a similarly moderate expression. The relative abundance of genes encoding key enzymes of the pathway were 5- to 
10-fold higher than those involved in cofactor biosynthesis. Overall, transcriptomic data indicate that the $\mathrm{H}_{4}$ MTP-pathway serves as the key pathway for formaldehyde oxidation in $M$. trichosporium $\mathrm{OB} 3 \mathrm{~b}$.

\section{FORMATE OXIDATION}

Formate is oxidized to $\mathrm{CO}_{2}$ by a NAD-dependent formate dehydrogenase in most, if not all, methanotrophs (Anthony, 1982). It has been suggested that most of the reducing power required for methane metabolism is produced by formaldehyde oxidation to formate and then to $\mathrm{CO}_{2}$ (Hanson and Hanson, 1996). It has been speculated that in microbes with a functional serine pathway, formate serves as a key branch point between assimilation and catabolism (Chistoserdova, 2011). NAD-dependent formate dehydrogenase from $M$. trichosporium OB3b has been purified and characterized (Jollie and Lipscomb, 1991). The enzyme is composed of four subunit types and contained flavin, iron, and molybdenum (Jollie and Lipscomb, 1991). The genome of $M$. trichosporium $\mathrm{OB} 3 \mathrm{~b}$ predicts one NAD-dependent molybdenumcontaining formate dehydrogenase encoded by $f d s A B G C D$ and an additional single copy of the alpha subunit ( $f d h A$ ). The two genes $f d s A$ and $f d h A$ share $81 \%$ identity. Only one of them, $f d s A$ as well as the rest of the $f d s$ cluster genes were expressed in the transcriptome (Table 2).

\section{C $_{1}$-ASSIMILATION: SERINE CYCLE}

It has been previously suggested that the serine cycle is the major pathway for $\mathrm{C}_{1}$-assimilation in $M$. trichosporium OB3b (Strom et al., 1974). All genetic elements essential for operation of the cycle were predicted in the genome and cluster together (Stein et al., 2010). However, genes of the pathway show deferent levels of expression (Table 2). While $s g a, g l y A$, and $m c l A$ have high expression levels, the rest of the genes involved in the pathway show modest expression (Table 2; Figure S4 in Supplementary Material). In addition to the serine-glyoxylate aminotransferase $(s g a)$, a key aminotransferase in the central metabolism of serine cycle microbes, moderate levels of expression were observed for two other aminotransferases, phosphoserine aminotransferase, and aspartate aminotransferase (Table 2).

The genome of $M$. trichosporium OB3b encodes two copies of phosphoenolpyruvate (PEP) carboxylase ( $p p c 1$ and $p p c 2)$. The two enzymes are only distantly related to each other and share $33 \%$ identity at the amino acid level. One of them, Ppcl, clusters with PEP carboxylases usually found in bacteria possessing the serine

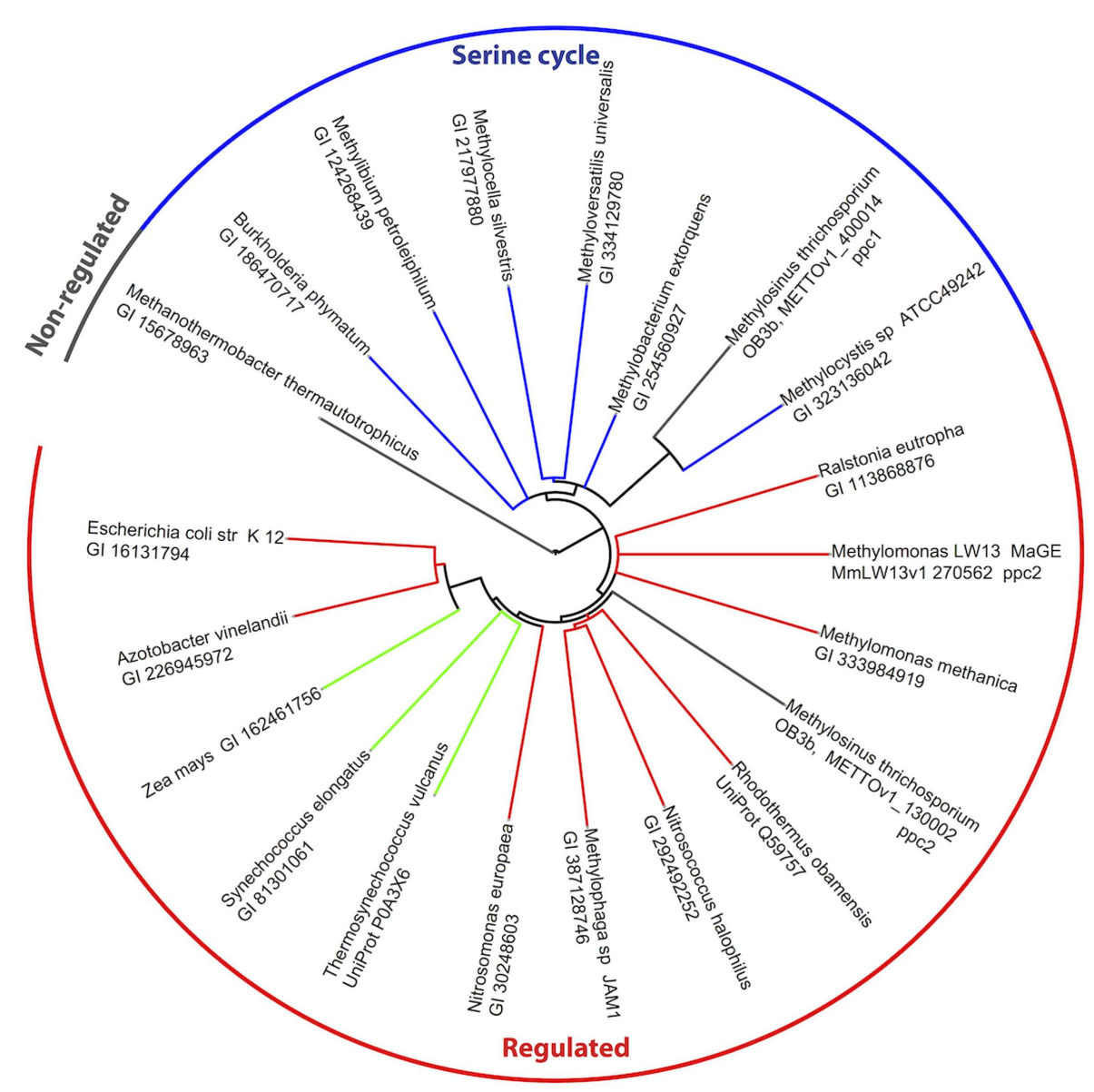

FIGURE 3 | Phylogenetic tree of phosphoenolpyruvate carboxylases. Sequence identifiers follow the source organism label. Sequences were aligned with MUSCLE v3.8.31 (Edgar, 2004) and the tree created with ClustalW2 2.0.12 (Larkin et al., 2007) and rendered with iTOL (Letunic and Bork, 2007). 
cycle for $\mathrm{C}_{1}$-assimilation (Figure 3 ). Serine cycle Ppcs belong to a "non-regulated" group of PEP carboxylases (Anthony, 1982). The activity of these enzymes is not controlled by intermediates of the TCA cycle or glycolysis/gluconeogenesis (Newaz and Hersh, 1975). The second homolog of Ppc ( $p p c 2)$ clusters with anaplerotic "regulated" PEP carboxylases, which are controlled by a variety of metabolic effectors (Takahashi et al., 1993; Kai et al., 2003). Both $p p c 1$ and $p p c 2$ transcripts demonstrate comparable levels of abundance in this study (Table 2). The sequences of the two genes were further investigated in an attempt to better understand the rationale for the enzymatic redundancy at the PEP to oxaloacetate conversion step. We used multiple sequence alignments of Ppc1, Ppc2, and other characterized PEP carboxylases and homology models (not shown) built from tensed and relaxed state crystal structures (Matsumura et al., 2002) to investigate the predicted allosteric regulation sites of these two enzymes. The alignment shows that only the catalytic elements, such as PEP-binding-site residues, are conserved in both proteins ( $\mathrm{Ppc} 1$ and $\mathrm{Ppc}$, Figure S6 in Supplementary Material). However, sequence features required for the allosteric regulation of the enzyme activity show several structural differences. The majority of the characterized bacterial PEP carboxylases are activated by acetyl-CoA, FBP, long-chain fatty acids, and $\mathrm{pGp}$. Inhibition occurs in the presence of aspartate and L-malate. In the case of $\mathrm{Ppcl}$ from $M$. trichosporium OB3b, two of the four highly conserved polar amino acids that bind allosteric inhibitors (e.g., aspartate, malate) were hydrophobic: L805 and A912 ( $\mathrm{K}$ and $\mathrm{N}$ in E. coli respectively) suggesting alternate inhibitors or a lack of sensitivity to L-malate and aspartate. The activator-binding residues were conserved except for a $\mathrm{R} 159$ instead of K. By contrast, Ppc2 was well conserved relative to the well characterized PEP carboxylases and for those with structures, only minor rearrangements of the monomeric interfaces were predicted. It is tempting to speculate that the presence of two functionally identical but differently regulated enzymatic systems in M. trichosporium OB3b evolved as a way to control flux through PEP-oxaloacetate in response to levels of the serine cycle and EMC pathway intermediates. The flux is never completely blocked, due to the insensitivity of Ppcl to the metabolic state of the cell. Increases in the intracellular levels of acetyl-CoA, aspartate, or malate (as a result of saturation of the downstream EMC pathway and the TCA cycle) can reduce the flux through the PEPoxaloacetate presumably twofold via allosteric inhibition and lack of activation of Ppc2 activity. In this case, $\mathrm{C}_{1}$-carbon assimilated via the serine cycle is re-directed to gluconeogenesis or converted into pyruvate.

Regeneration of glyoxylate is an essential part of the serine cycle (Anthony, 1982, 2011; Peyraud et al., 2009). Like other obligate methanotrophic bacteria, $M$. trichosporium OB3b lacks isocitrate lyase, a key enzyme of the glyoxylate shunt (Trotsenko and Murrell, 2008). Homologs of enzymes involved in the ethylmalonyl-CoA (EMC) pathway, an alternative route for glyoxylate regeneration (Peyraud et al., 2009), were identified in the draft genomes of $M$. trichosporium OB3b and another obligate methanotroph Methylocystis sp. (Stein et al., 2010, 2011). However, a functional EMC pathway has not yet been demonstrated in methanotrophs. Furthermore, the recent investigation of PHB-metabolism in Methylocysctis parvus OBBP, an alphaproteobacterial methanotroph, suggested that this metabolic module can not supply $\mathrm{C}_{2}$ (glyoxylate) units for biosynthesis (Pieja et al., 2011). As the initial steps of the EMC pathway are shared with PHB biosynthesis [acetyl-CoA acetyltransferase ( $p h a A)$ and acetoacetyl-CoA reductase ( $p h a B)$, see Figure 1] in context with the data presented by Pieja et al. (2011) call into question the operation of the EMC pathway in methanotrophs.

We found that genes encoding the initial steps of the PHBsynthesis (phaA/phaB) show moderate levels of expression. As could be expected for cells in early-mid exponential growth, the expression of the gene encoding PHB synthase ( $p h a C$ ) was low. The data are consistent with previous observations of high activity of PhaA and PhaB and low activity of PHB synthase (PhaC) in exponentially grown cells of $M$. trichosporium OB3b (Williams, 1988; Doronina et al., 2008). The PHB-degradation pathway genes, including 3-hydroxybutyrate dehydrogenase, acetoacetate decarboxylase, and acetoacetyl-coenzymeA synthetase, show modest expression levels (Table 2).

All homologs of the EMC pathway enzymes were expressed in M. trichosporium OB3b during growth on methane (Table 2). Several putative acetyl/propionyl-CoA carboxylases are predicted in the genome, however only METTOv1_200020 (putative $P p c A$ ) and METTOv1_220035 (putative $p p c B$ ) were expressed. Furthermore, the PpcAB and crotonyl-CoA reductase ( $c c r)$ genes display the highest level of expression among all $\mathrm{CO}_{2}$-fixing enzymes in the M. trichosporium OB3b transcriptome. Thus, the transcriptional profile of $M$. trichosporium OB3b indicates the methanotroph may possess an active EMC pathway.

\section{$C_{1}$-ASSIMILATION: TCA CYCLE AND ANAPLEROTIC $\mathrm{CO}_{2}$-FIXATION}

All previous enzymatic studies predict that the tricarboxylic acid cycle (TCA cycle) in alphaproteobacterial methanotrophs is complete (Trotsenko and Murrell, 2008). However, the functional role of this metabolic pathway in methanotrophs is not fully understood. It has been suggested that the main role of the TCA cycle in the methanotrophs is carbon assimilation rather than energy production, due to low enzyme activity and lack of pyruvate dehydrogenase (Trotsenko, 1976; Anthony, 1982; Shishkina and Trotsenko, 1982; Trotsenko and Murrell, 2008). However, labeling studies on acetate and pyruvate utilization have predicted the presence of a catabolic TCA cycle in type II methanotrophs (Wadzink and Ribbons, 1975; reviewed in Higgins et al., 1981). In silico genome analysis indicates that $M$. trichosporium $\mathrm{OB} 3 \mathrm{~b}$ contains predicted genes for all key enzymes of the TCA cycle and pyruvate dehydrogenase $(p d h)$. All of these genes were expressed (Table 2). These steps of the TCA cycle are shared between the EMC pathway and the serine cycle (Figure 1). De novo transcriptome assembly indicated that $M$. trichosporium OB3b possesses an additional homolog of succinate:ubiquinone oxidoreductase ( sucABCD, Table S1 in Supplementary Material). Genes encoding the succinate:ubiquinone oxidoreductase and succinyl-CoA synthase $(s u c C D)$ are among the most highly expressed TCA cycle functions. The reductive branch of the pathway (including genes for citrate synthase, aconitase, isocitrate dehydrogenase, and 2-ketoglutarate dehydrogenase) displays moderate-tolow expression. Low expression of $p d h$ genes is consistent with the 
previous enzymatic studies that show low/no activity of pyruvate dehydrogenase (Trotsenko, 1976).

It has been shown that the $\mathrm{CO}_{2}$-fixation potential is maximal during early stages of logarithmic growth (Park et al., 1991, 1992). However, data on carboxylation system(s) in M. trichosporium $\mathrm{OB} 3 \mathrm{~b}$ are controversial. Most previous enzymatic studies predict that the PEP carboxylase (Ppc), a key enzyme of the serine cycle, is the major entry point for $\mathrm{CO}_{2}$ in alphaproteobacterial methanotrophs (Shishkina and Trotsenko, 1982). On the other hand Naguib (1979) has shown that M. trichosporium OB3b possesses different carboxylation systems, including membrane bound and cytoplasmic enzymes. It could be predicted that the EMC pathway also contributes to $\mathrm{CO}_{2}$ assimilation. In silico analysis of the genome sequence also revealed that in addition to the $\mathrm{CO}_{2}$-fixing functions described above, genes for $\mathrm{NAD}(\mathrm{P})$-dependent malic enzyme (mae), acetyl-CoA carboxylase $(\operatorname{acc} A B D)$, phosphoribosyl aminoimidazole carboxylase, pyruvate carboxylase $(p c x)$, and a putative 2-oxoacid ferredoxin oxidoreductase are all present. All of these genes were expressed (Table 2).

\section{GLYCOLYSIS/GLUCONEOGENESIS AND PENTOSE-PHOSPHATE PATHWAYS}

The absence of enzymatic activity for the initial steps of the gluconeogenic pathway including pyruvate-PEP or oxaloacetate-PEP conversions was one of the most common explanations for the inability of alphaproteobacterial methanotrophic bacteria to grow on poly-carbon compounds such as pyruvate or acetate (Patel et al., 1979; Shishkina and Trotsenko, 1982). No homolog of PEPcarboxykinase was found in the $M$. trichosporium OB3b genome. However, contrary to expectations based on enzymatic inferences, a set of pyruvate-acetyl-CoA, pyruvate-PEP, and pyruvate-malate interconversions could be predicted from the genome annotation. Homologs of PEP synthase ( $p p s)$, pyruvate kinase ( $p y k 1$ and $p y k 2$ ), and pyruvate phosphate dikinase were detected. The relative abundances of $p y k 1, p p s$, and $p d k$ transcripts were low, but a second pyruvate kinase ( $p y k 2$ ) displayed modest expression (Table 2).

During growth on $\mathrm{C}_{1}$ compounds (methane or methanol), gluconeogenesis starts with conversion of 2-phosphoglycerate into 3-phosphoglycerate by phosphoglycerate mutase ( $\mathrm{pgm})$. This metabolic step represents the main branch point of the serine cycle. Four homologs of pgm were identified in the M. trichosporium OB3b genome. Three of them (METTOv1_10180, METTOv1_100061, and METTOv1_680013) were expressed at tested conditions. Homologs of the genes for the rest of the enzymes in the pathway were detected in the genome, mostly in single copies. All gene transcripts were observed in the RNA-Seq data (Table 2).

The genome analysis suggests that the pentose-phosphate pathway (PPP) is incomplete in M. trichosporium OB3b. Glucose6-phosphate dehydrogenase, gluconolactonase and phosphogluconate dehydrogenase (oxidative PPP), and transaldolase or sedoheptulose bisphosphatase (non-oxidative PPP), are missing in the genome. In addition, no homologs of the genes were detected among de novo assembled transcripts. The lack of the oxidative branch of the PPP is consistent with previous enzymatic data and the inability of alphaproteobacterial methanotrophs to utilize sugars. However if the non-oxidative PPP operates as a route for generation of ribose-5-phosphate for the synthesis of nucleotides, an unknown enzyme must be involved in the sedoheptulose-phosphate interconversion. One possible system is a pyrophosphate-dependent phosphofructokinase (Pfk). It has been shown that Pfks from methanotrophic bacteria have surprisingly high affinity for sedoheptulose phosphate, and can catalyze the conversion of sedoheptulose-1,7-bisphosphate to sedoheptulose-7-phosphate (Reshetnikov et al., 2008; Rozova et al., 2012). It is possible that Pfk contributes to sedoheptulose1,7-bisphosphate conversion in M. trichosporium OB3b.

\section{LIPID METABOLISM}

Methane oxidation via particulate methane monooxygenase is linked to formation of extensive intracellular membranes. It has been shown that lipid/biomass content of $M$. trichosporium OB3b cells grown on methane is $9.2 \%$ and that phospholipids represent a significant fraction of membrane lipids (83.4\%) (Weaver et al., 1975; Guckert et al., 1991). Concurrent with previous observation, genes essential for biosynthesis of major fatty acids (stearic, oleic, and palmitoleic acids) and phospholipids (including phosphotidylcholine, phosphatidylglycerol, phosphatidylserine, and phosphatidylethanolamine) show moderate level of expression (Table S2 in Supplementary Material).

\section{NITROGEN, COPPER, AND IRON METABOLISM}

The pathways of nitrogen assimilation have been studied in a number of obligate methanotrophic species including $M$. trichosporium OB3b. Methanotrophs are able to grow with ammonia, nitrate, and molecular nitrogen as N-sources (Whittenbury et al., 1970; Shishkina and Trotsenko, 1979; Murrell and Dalton, 1983a,b; Chu and Alvarez-Cohen, 1998; Kim and Graham, 2001). No activities of alanine or glutamate dehydrogenases were detected in cell extracts of $M$. trichosporium OB3b grown on any source of nitrogen (Shishkina and Trotsenko, 1979; Murrell and Dalton, 1983a,b). It has been concluded that ammonia was assimilated exclusively via the glutamine synthetase/glutamate synthase pathway (Murrell and Dalton, 1983b).

In this study, cells of $M$. trichosporium OB3b were grown using nitrate as the $\mathrm{N}$-source. Despite the presence of an exogenous source of nitrogen, some (very low) expression of the nitrogenase gene cluster was observed. Relative expression of nitrogenase structural genes (nifHDK) was about four to five times higher than expression of the chaperone and cofactor biosynthesis genes (Table S2 in Supplementary Material). High expression of genes involved in assimilatory nitrate reduction, including the nitrate transporter ( $n r t A)$, nitrate reductase (nasA), and nitrite reductase $(n a s D E)$ was detected. Interestingly, moderate expression of a putative ammonium transporter (METTOv1_130049) was detected, although a gene cluster with putative involvement in hydroxylamine detoxification (METTOv1_230076-78), which should only be needed under conditions of high ammonium concentration, showed low expression (Table 2). The gene encoding cytochrome $c^{\prime}$-alpha (METTOv1_560023), a protein implicated in NOx detoxification, was moderately expressed. Homologs of alanine dehydrogenase (METTOv1_280018) and glutamate dehydrogenase (METTOv1_190023) were identified; however, neither gene was expressed (Table 2). High expression of glutamate synthase (both $\mathrm{NADH}$ and Fd-dependent), glutamate-ammonia 
ligase (METTOv1_200046), and Type I glutamine synthetase (METTOv1_200048) was observed. Based on these transcriptomic studies and genome analysis, the only pathway for alanine biosynthesis is transamination of pyruvate. The most likely enzymatic system for this conversion is the serine-glyoxylate aminotransferase (Sga), which is known to catalyze serine-pyruvate transamination (Liepman and Olsen, 2001). It has been shown that alanine may serve as alternative substrate for SGA in methylotrophs (Karsten et al., 2001).

Copper is an important microelement in the physiology of methanotrophic bacteria possessing pMMO (Anthony, 1982). Methanotrophic bacteria synthetize methanobactin (Mb), a copper-chelating compound (Kim et al., 2004; Balasubramanian and Rosenzweig, 2008; Semrau et al., 2010). It has been suggested that $\mathrm{Mb}$ provides copper for the regulation and activity of methane oxidation machinery in methanotrophs (Balasubramanian et al., 2010; Semrau et al., 2010). It has been shown that $\mathrm{Mb}$ is a peptide-derived molecule. A gene encoding the Mb precursor in M. trichosporium OB3b has recently been identified (Krentz et al., 2010). We found that the Mb-gene is among the top 5\% most abundant transcripts despite the fact that the culture in our experiments was grown with sufficient $\mathrm{Cu}$ (Table 2). It is not known how $\mathrm{Mb}$ is synthesized or cleaved, however it has been suggested that genes downstream of $m b$ are involved (Krentz et al., 2010). These genes were also expressed, but the expression level was low.

Iron is another essential metal in $\mathrm{C}_{1}$-metabolism. It has been previously observed that $M$. trichosporium $\mathrm{OB} 3 \mathrm{~b}$ can produce a Fechelating compound (Yoon et al., 2010); however the siderophore structure and pathways for its biosynthesis remain to be discovered. The production of a fluorescent compound was observed on plates at tested growth conditions (data not shown). Our transcriptomic studies revealed relatively high expression of genes homologous to those involved in pyoverdine ( $p v d)$ I biosynthesis, excretion, uptake, and regulation (Table 2), making this a possibility for a siderophore. All four essential non-ribosomal peptide synthetases ( $p v d L I J D)$ were identified. Unfortunately, the $p v d$ genes are represented in fragments in the current genome assembly, making it impossible to predict the order of the amino acids in the peptide product.

\section{CONCLUSION}

In this work we performed genomic- and transcriptomic-based reconstruction of the central metabolic pathways in Methylosinus trichosporium $\mathrm{OB} 3 \mathrm{~b}$ grown on methane as a sole source of carbon and energy. The overview of the methane metabolism is summarized in Figure 1. While some metabolic functions correlate well with previous enzymatic and genetic studies, several novel functions were detected and characterized. The major outcomes of our work are listed below:

1. Exceptionally high expression of pMMO in comparison to other central pathway functions (such as methanol or formaldehyde oxidation) implies a relatively low turn over at the first step of methane conversion.

2. We propose that M. trichosporium OB3b uses the EMC variant of the serine cycle for carbon assimilation. In addition to carbon fixing reactions of the EMC-serine cycle, a number of carboxylation reactions are predicted. The role of $\mathrm{CO}_{2}$ fixation during methanotrophic growth has further been explored by Yang et al. (2013).

3. The diversity of predicted reactions at the PEP-pyruvateoxaloacetate node suggests that metabolic interconversions may play an important role in the distribution of carbon flux between the serine cycle, EMC pathway, and TCA cycle. In M. trichosporium OB3b the PEP-oxaloacetate conversion is predicted to be performed by two enzymatic systems under different metabolic control. Increases in the intracellular pools of malate, aspartate, and acetyl-CoA could activate flow of $\mathrm{C}_{1}$-derived carbon into gluconeogenesis and/or pyruvate. Our results indicate that multiple PEP-pyruvate conversion reactions may be taking place in the strain during growth on methane as a way to regenerate energy and to provide pyruvate for biosynthesis. Due to the lack of PEP-carboxykinase, the PEP synthesis from $\mathrm{C}_{4}$ compounds is also possible and could be achieved via decarboxylation of malate (MalE). Two reactions are predicted for PEP synthesis from pyruvate, however both of them seem to be of minor importance during growth on methane.

4. A number of transamination reactions contribute to carbon partitioning and nitrogen assimilation. It has been predicted that the growth of majority of alphaproteobacterial methylotrophic bacteria is $\mathrm{NAD}(\mathrm{P}) \mathrm{H}$-limited due to the high $\mathrm{NADH}$ requirements for formaldehyde assimilation via serine cycle (Anthony, 1978). Biosynthesis of key amino acids (such as alanine, glutamate and aspartate) via transamination seems to be a rational metabolic compensation to $\mathrm{NAD}(\mathrm{P}) \mathrm{H}$-limitation.

5. While copper acquisition is quite well characterized in $M$. trichosporium OB3b, relatively little is known about iron uptake systems. Transcriptomic data provide initial evidence for siderophore production in this methanotroph.

\section{MATERIALS AND METHODS STRAIN AND CULTIVATION CONDITIONS}

Methylosinus trichosporium strain OB3b was kindly provided by Dr. Lisa Stein. The culture was grown in $250 \mathrm{~mL}$ glass bottles on modified NMS medium (Whittenbury et al., 1970) containing (per liter of distilled water): $1 \mathrm{~g} \cdot \mathrm{KNO}_{3}, 1 \mathrm{~g} \cdot \mathrm{MgSO}_{4} \cdot 7 \mathrm{H}_{2} \mathrm{O}$, $0.134 \mathrm{~g} \cdot \mathrm{CaCl}_{2} \cdot 2 \mathrm{H}_{2} \mathrm{O}, 0.25 \mathrm{~g} \cdot \mathrm{KH}_{2}-\mathrm{PO}, 0.7 \mathrm{~g} \cdot \mathrm{Na}_{2} \mathrm{HPO}_{4} \cdot 12 \mathrm{H}_{2} \mathrm{O}$, and $2 \mathrm{~mL}$ of trace elements solution. The trace elements solution contained $0.5 \mathrm{~g} \cdot \mathrm{Na}_{2}$-EDTA, $1.0 \mathrm{~g} \cdot \mathrm{FeSO}_{4} \cdot 7 \mathrm{H}_{2} \mathrm{O}, 0.75 \mathrm{~g} \cdot \mathrm{Fe}-$ EDTA, $0.8 \mathrm{~g} \cdot \mathrm{ZnSO}_{4} \cdot 7 \mathrm{H}_{2} \mathrm{O}, 0.005 \mathrm{~g} \cdot \mathrm{MnCl}_{2} \cdot 4 \mathrm{H}_{2} \mathrm{O}, 0.03 \mathrm{~g} \cdot \mathrm{H}_{3} \mathrm{BO}_{3}$, $0.05 \mathrm{~g} \cdot \mathrm{CoCl}_{2} \cdot 6 \mathrm{H}_{2} \mathrm{O}, 0.4 \mathrm{~g} \cdot \mathrm{Cu}-\mathrm{EDTA}, 0.6 \mathrm{~g} \cdot \mathrm{CuCl}_{2} \cdot 2 \mathrm{H}_{2} \mathrm{O}, 0.002 \mathrm{~g}$. $\mathrm{NiCl}_{2} \cdot 6 \mathrm{H}_{2} \mathrm{O}$, and $0.05 \mathrm{~g} \cdot \mathrm{Na}_{2} \mathrm{MoO}_{4} \cdot 2 \mathrm{H}_{2} \mathrm{O}$. The bottles were sealed with rubber stoppers and aluminum caps, then $50 \mathrm{~mL}$ of methane was added to the $200 \mathrm{~mL}$ headspace. Bottles were shaken at 250 $\mathrm{RPM}$ at $30^{\circ} \mathrm{C}$ for $1-4$ days.

\section{GROWTH PARAMETERS AND METHANE CONSUMPTION RATE MEASUREMENTS}

Methane consumption rates and cell density $\left(\mathrm{OD}_{600}\right)$ were measured in triplicate as cultures grew. Methane measurements were made on a Shimadzu Gas Chromatograph GC-14A, using the FID detection with helium as the carrier gas. Concentrations 
were deduced from standard curves. $\mathrm{OD}_{600}$ was measured on a Beckman DU ${ }^{\circledR} 640 \mathrm{~B}$ spectrophotometer in plastic $1.5 \mathrm{~mL}$ cuvettes with a $1 \mathrm{~cm}$ path length.

\section{RNA-seq}

Two replicate cultures were grown to mid exponential phase $\left(\mathrm{OD}_{600} 0.29 \pm 0.01\right)$ for approximately $24 \mathrm{~h}$, then collected by pouring $45 \mathrm{~mL}$ of culture into $50 \mathrm{~mL}$ tubes containing $5 \mathrm{~mL}$ of stop solution comprised of 5\% water-equilibrated phenol, $\mathrm{pH} 6.6$ (Sigma; St. Louis, MO, USA), and 95\% ethanol (200 Proof; Deacon Labs, Inc., King of Prussia, PA, USA). The cells were collected by centrifugation at $4,300 \times g$ at $4^{\circ} \mathrm{C}$ for $10 \mathrm{~min}$. The resultant pellet was re-suspended in $0.75 \mathrm{~mL}$ of extraction buffer [ $2.5 \%$ CTAB (Sigma; St. Louis, MO, USA), 0.7 M NaCl, and 0.075 M pH 7.6 phosphate buffer] and transferred to a $2 \mathrm{~mL}$ sterilized screw-cap tube containing $0.75 \mathrm{~mL}$ of phenol:chloroform:isoamylic alcohol with a volume ratio of 25:24:1 (Ambion ${ }^{\circledR}$; Austin, TX, USA), $0.5 \mathrm{~g}$ of $0.1 \mathrm{~mm}$ silica beads (Biospec products; Bartlesville, OK, USA), $0.2 \%$ SDS (Ambion ${ }^{\circledR}$; Austin, TX, USA), and 0.2\% lauryl sarkosine (Sigma; St. Louis, MO, USA). The mixtures were homogenized in a bead beater (Mini-Beadbeater; Biospec Products; Bartlesville, OK, USA) for $2 \mathrm{~min}$ ( $75 \%$ of the maximum power). The resulting slurry was centrifuged for $5 \mathrm{~min}$ at $4^{\circ} \mathrm{C}$ and $20,800 \times \mathrm{g}$. The aqueous layer was transferred to a fresh tube containing $0.75 \mathrm{~mL}$ of chloroform:isoamylic alcohol with a volumetric ratio of 24:1 (Sigma; St. Louis, MO, USA) and centrifuged again for $5 \mathrm{~min}$ at $4^{\circ} \mathrm{C}$ and $20,800 \times g$ to remove dissolved phenol. The aqueous phase was transferred to a new tube. $\mathrm{MgCl}_{2}$ (final concentration $3 \mathrm{mM}$ ), sodium acetate ( $10 \mathrm{mM}, \mathrm{pH} 5.5)$, and $0.8 \mathrm{~mL}$ icecold isopropanol were added. Nucleic acids were transferred to $-80^{\circ} \mathrm{C}$ for overnight precipitation. Precipitated samples were centrifuged for $45 \mathrm{~min}$ at $4^{\circ} \mathrm{C}$ and $14,000 \mathrm{RPM}(20,800 \times \mathrm{g})$, washed with $0.5 \mathrm{~mL}$ of $75 \%$ ethanol (made from 200 proof; Deacon Labs, Inc., King of Prussia, PA, USA), and dried for $15 \mathrm{~min}$ at room temperature.

An RNeasy Mini Kit (Qiagen(C) Venlo, Netherlands) with two types of DNA digestions was used to isolate the mRNA. Initially, the DNA/RNA pellet was re-suspended in $80 \mathrm{~mL}$ of a DNase I (RNase-free) mixture (Ambion ${ }^{\circledR}$; Austin, TX, USA) and incubated for $30 \mathrm{~min}$ at $37^{\circ} \mathrm{C}$. Then, the samples were purified on RNeasy Mini Kit columns as described in the RNA cleanup section of the manual, including the optional on-column DNAse digestion. The MICROBExpress ${ }^{\mathrm{TM}}\left(\right.$ Ambion $^{\circledR}$; Austin, TX, USA) kit was applied to each sample to reduce the rRNA concentration and increase the mRNA sequencing depth.

The sample quality was monitored with three techniques: (1) by electrophoresis in TAE buffer in 1\% agarose gels (2) using an Agilent 2100 Bioanalyzer with Agilent RNA 6000 Nano-kit as suggested by the manufacturer, and (3) by real-time reversetranscriptase PCR (RT-RT PCR) with 16S rRNA (27F/536R) and pmoA-specific (Auman et al., 2001) primers.

\section{TRANSCRIPT SEQUENCING, ALIGNMENT, AND MAPPING}

Enriched RNA samples (i.e., two biological replicates) were submitted to the University of Washington's High-Throughput Sequencing Solutions Center on dry ice for single-read Illumina ${ }^{\circledR}$ sequencing (Department of Genome Sciences, University of
Washington $^{2}$ ). The replicates were aligned to the reference genome using BWA under default parameters (Li and Durbin, 2009). The "METTOv1" genome sequence was downloaded from MaGE (Vallenet et al., 2006). The single large pseudo scaffold distributed by MaGE was split into 187 separate contigs at each stretch of $N$ bases. In addition, chimeric contigs from the assembly and low quality gene calls were removed (Table S5 in Supplementary Material). The summary of RNA-seq (Illumina) reads can be found in Table S4 in Supplementary Material. The METTOv1 genome did not have a complete $p m o C A B$ cluster suitable for alignment. In order to include $p m o C A B$, a separate alignment run was performed with the previously published sequence of this gene cluster (Holmes et al., 1995). After the alignment with BWA, SAM tools was used to generate a pileup file that was loaded into a MySQL database for normalization from Reads Per Kilobase of gene per Million mapped reads (RPKM) to coding sequences (Mortazavi et al., 2008).

\section{TRANSCRIPTION SITE MAPPING AND TRANSCRIPTOME BASED GENE ASSEMBLY}

The reads mapped at each base position in the genomic scaffolds generated from the pileup were manually examined to identify putative transcription starts and stops. Briefly, reads mapped per base data for the two replicates were plotted on a log scale. The boundary of a rapid transition from near zero reads mapped to 10, 100 RPKM or more that was upstream of a gene start was designated a transcription start. Stops were similarly identified as a rapid transition to low numbers of reads mapped downstream of a gene termination codon.

Given the fragmented nature of the M. trichosporium OB3b genome, we performed de novo assembly of the RNA-Seq reads, in an attempt to identify transcripts whose genomic sequences were incomplete. The assembly was performed with Velvet 1.2.06 (Zerbino and Birney, 2008) and Oases 0.2.08 (Schulz et al., 2012). The oases pipeline tool distributed with Oases was used to survey assemblies across the range of odd k-mers from 17 to 35 where the minimum fragment length was set to $100 \mathrm{bp}$. The final merged assembly from the pipeline tool was stripped down to the highest confidence transcript for each locus with confidence ties resolved by taking the longest sequence. The high confidence assembled transcripts were aligned to the M. trichosporium OB3b scaffolds using BLASTn. Transcripts without significant matches were aligned with BLASTx to the protein non-redundant database, as retrieved on January 13, 2012.

\section{ACKNOWLEDGMENTS}

This project was funded by the DOE (DE-SC0005154). Authors are very grateful to Mary E. Lidstrom, Ludmila Chistoserdova, and Valentina N. Khmelenina for many insightful suggestions on the manuscript.

\section{SUPPLEMENTARY MATERIAL}

The Supplementary Material for this article can be found online at http://www.frontiersin.org/Microbiological_Chemistry/10.3389/ fmicb.2013.00040/abstract

\footnotetext{
${ }^{2}$ http://www.htseq.org/
} 
Figure S1 | RNA-Seq reads mapped per base relative to start of pmo-operon. Left, the average number of reads mapped to the region -330 to -270 upstream from the start of $p m o C$ for two biological replicates. The sequence at each base is shown above the bars. Right, the range (shown in red) and mean of two biological replicates (shown as black line) for the number of reads mapped per base for the coding and downstream region of the pmo-operon.

Figure S2 | Genetic organization and relative expression (RPKM) of the mxa gene cluster (A), the pqq gene cluster (B) and cluster of genes encoding reactions of the $\mathrm{H}_{4}$ MPT-linked $\mathrm{C} 1$ transfer pathway (C).

Figure S3 | RNA-Seq reads mapped per base relative to start of $\boldsymbol{m x a F}$ ORF. Left, the average number of reads mapped to the region -200 to -140 upstream from the start of $m x a F$ for two biological replicates. The sequence at each base is shown above the bars. Right, the range (shown in red) and mean of two biological replicates (shown as black line) for the number of reads mapped per base for the coding and downstream region of the mxaF cluster.

Figure S4 | RNA-Seq reads mapped per base relative to start of serine cycle gene operon. The log10 average number of reads mapped at each base from biological replicates one and two is shown. In (A), the upstream location spanning -250 to -190 from putative start of $\mathrm{ftfL}$. (B) The expression over the entire operon. Note the several drop to near zero upstream indicating the operon is not co-transcribed. (C) The -230 to -170 region upstream from sga

\section{REFERENCES}

Anthony, C. (1978). The prediction of growth yields in methylotrophs. $J$. Gen. Microbiol. 104, 91-104.

Anthony, C. (1982). The Biochemistry of Methylotrophs. New York: Academic Press Inc.

Anthony, C. (2002). Methanol dehydrogenase, a PQQ-containing quinoprotein dehydrogenase. Subcell. Biochem. 35, 73-117.

Anthony, C. (2011). How half a century of research was required to understand bacterial growth on $\mathrm{C} 1$ and $\mathrm{C} 2$ compounds; the story of the serine cycle and the ethylmalonyl-CoA pathway. Sci. Prog. 94, 109-137.

Anthony, C., Ghosh, M., and Blake, C. C. (1994). The structure and function of methanol dehydrogenase and related quinoproteins containing pyrrolo-quinoline quinone. Biochem. J. 304, 665-674.

Auman, A. J., Speake, C. C., and Lidstrom, M. E. (2001). nifH sequences and nitrogen fixation in type I and type II methanotrophs. Appl. Environ. Microbiol. 67, 4009-4016.

Balasubramanian, R., and Rosenzweig, A. C. (2008). Copper methanobactin: a molecule whose time has come. Curr. Opin. Chem. Biol. 12, 245-249.

Balasubramanian, R., Smith, S. M., Rawat, S., Yatsunyk, L. A., Stemmler, T. L., and Rosenzweig, A. C. (2010). Oxidation of methane by a biological dicopper centre. Nature $465,115-119$.
Berube, P. M., and Stahl, D. A. (2012). The divergent AmoC3 subunit of ammonia monooxygenase functions as part of a stress response system in Nitrosomonas europaea. J. Bacteriol. 189, 3448-3456.

Caccamo, M. A., Malone, C. M., and Rasche, M. E. (2004). Biochemical characterization of a dihydromethanopterin reductase involved in tetrahydromethanopterin biosynthesis in Methylobacterium extorquens AM1. J. Bacteriol. 186, 2068-2073.

Chen, Y., Crombie, A., Rahman, M. T., Dedysh, S. N., Liesack, W., Stott, M. B., et al. (2010). Complete genome sequence of the aerobic facultative methanotroph Methylocella silvestris BL2. J. Bacteriol. 192, 3840-3841.

Chistoserdova, L. (2011). Modularity of methylotrophy, revisited. Environ. Microbiol. 13, 2603-2622.

Chistoserdova, L., Kalyuzhnaya, M. G., and Lidstrom, M. E. (2009). The expanding world of methylotrophic metabolism. Annu. Rev. Microbiol. 63, 477-499.

Chistoserdova, L., Rasche, M. E., and Lidstrom, M. E. (2005). Novel dephosphotetrahydromethanopterin biosynthesis genes discovered via mutagenesis in Methylobacterium extorquens AM1. J. Bacteriol. 187, 2508-2512.

Chistoserdova, L., Vorholt, J. A., Thauer, R. K., and Lidstrom, M. E. (1998). linking methylotrophic bacteria and $\mathrm{C} 1$ transfer enzymes and coenzymes

Bases from the +strand are shown across the top of the figure. (D) The -270 to -210 region upstream of $m c / A$.

Figure S5 | RNA-Seq reads mapped per base relative to start of fae1-1. Left, the average number of reads mapped to the region -235 to -185 upstream from the start of fae1-1 gene for two biological replicates. The sequence at each base is shown above the bars. Right, the range (shown in red) and mean of two biological replicates (shown as black line) for the number of reads mapped per base for the coding and downstream region of the fae1-1 and fae1-2 genes.

Figure S6 | Primary structure alignment for phosphoenolpyruvate carboxylases (Ppc1 and Ppc2) from M. trichosporium OB3b and Ppc-homologs.

\section{Table S1 |Transcripts detected by de novo assembly RNA-Seq data.}

Table S2 | Gene expression profile in methane-grown cells of $\boldsymbol{M}$. trichosporium OB3b. Values represent reads per kilobase of coding sequence per million (reads) mapped (RPKM).

Table S3 | Summary of putative transcription site mapping (Note that the published sequences need references added).

Table S4 | Summary of RNA-seq (Illumina) reads.

Table S5 | Genes removed from reference scaffold before alignment.

methanogenic archaea. Science 281, 99-102.

Chu, K. H., and Alvarez-Cohen, L. (1998). Effect of nitrogen source on growth and trichloroethylene degradation by methane-oxidizing bacteria. Appl. Environ. Microbiol. 64, 3451-3457.

Crowther, G. J., Kosály, G., and Lidstrom, M. E. (2008). Formate as the main branch point for methylotrophic metabolism in Methy lobacterium extorquens AM1. J. Bacteriol. 190, 5057-5062.

Dam, B., Kube, M., Dam, S., Reinhardt, R., and Liesack, W. (2012a). Complete sequence analysis of two methanotroph-specific repABC-containing plasmids from Methylocystis sp. strain SC2. Appl. Environ. Microbiol. 78, 4373-4379.

Dam, B., Dam, S., Kube, M., Reinhardt, R., and Liesack, W. (2012b). Complete genome sequence of Methylocystis sp. strain SC2, an aerobic methanotroph with high-affinity methane oxidation potential. J. Bacteriol. 194, 6008-6009.

Doronina, N. V., Ezhov, V. A., and Trotsenko, Yu. A. (2008). Growth of Methylosinus trichosporium $\mathrm{OB} 3 \mathrm{~b}$ on methane and poly-betahydroxybutyrate biosynthesis. Prikl. Biokhim. Mikrobiol. 44, 182-185.

Dunfield, P. F., Yuryev, A., Senin, P. Smirnova, A. V., Stott, M. B., Hou, S., et al. (2007). Methane oxidation by an extremely acidophilic bacterium of the phylum Verrucomicrobia. Nature 450, 879-882.
Edgar, R. C. (2004). MUSCLE: multiple sequence alignment with high accuracy and high throughput. Nucleic Acids Res. 32, 1792-1797.

Elango, N., Radhakrishnan, R., Froland, W. A., Wallar, B. J., Earhart, C. A., Lipscomb, J. D., et al. (1997). Crystal structure of the hydroxylase component of methane monooxygenase from Methylosinus trichosporium OB3b. Protein Sci. 6, 556-568.

EPA. (1993). Emerging Technology Summary Pilot-Scale Demonstration of a Two-Stage Methanotrophic Bioreactor for Biodegradation of Trichloroethylene in Groundwater. Available at: http://nepis.epa.gov

Fitch, M. W., Speitel, G. E., and Georgiou, G. (1996). Degradation of trichloroethylene by methanolgrown cultures of Methylosinus trichosporium OB3b PP358. Appl. Environ. Microbiol. 62, 1124-1128.

Gilbert, B., McDonald, I. R., Finch, R., Stafford, G. P., Nielsen, A. K., and Murrell, J. C. (2000). Molecular analysis of the pmo (particulate methane monooxygenase) operons from two type II methanotrophs. Appl. Environ. Microbiol. 66, 966-975.

Guckert, J. B., Ringelberg, D. B., White, D. C., Hanson, R. S., and Bratina, B. J. (1991). Membrane fatty acids as phenotypic markers in the polyphasic taxonomy of methylotrophs within the Proteobacteria. J. Gen. Microbiol. 137, 2631-2641 
Hakemian, A. S., Kondapalli, K. C., Telser, J., Hoffman, B. M., Stemmler, T. L., and Rosenzweig, A. C. (2008). The metal centers of particulate methane monooxygenase from Methylosinus trichosporium OB3b. Biochemistry 47, 6793-6801.

Hakemian, A. S., and Rosenzweig, A. C. (2007). The biochemistry of methane oxidation. Annu. Rev. Biochem. 76, 223-241.

Hanson, R. S., and Hanson, T. E. (1996). Methanotrophic bacteria. Microbiol. Rev. 60, 439-471.

Higgins, I. J., Best, D. J., Hammond, R. C., and Scott, D. (1981). Methaneoxidizing microorganisms. Microbiol. Rev. 45, 556-590.

Holmes, A. J., Costello, A., Lidstrom, M. E., and Murrell, J. C. (1995). Evidence that particulate methane monooxygenase and ammonia monooxygenase may be evolutionarily related. FEMS Microbiol. Lett. 132, 203-208.

Hou, C. T., Patel, R., Laskin, A. I., and Barnabe, N. (1979). Microbial oxidation of gaseous hydrocarbons: epoxidation of $\mathrm{C} 2$ to $\mathrm{C} 4$ n-alkenes by methylotrophic bacteria. Appl. Environ. Microbiol. 38, 127-134.

Hou, S., Makarova, K. S., Saw, J. H., Senin, P., Ly, B. V., Zhou, Z., et al. (2008). Complete genome sequence of the extremely acidophilic methanotroph isolate V4, Methylacidiphilum infernorum, a representative of the bacterial phylum Verrucomicrobia. Biol. Direct 3, 26.

Jollie, D. R., and Lipscomb, J. D. (1991). Formate dehydrogenase from Methylosinus trichosporium OB3b. Purification and spectroscopic characterization of the cofactors. $J$. Biol. Chem. 266, 21853-21863.

Kai, Y., Matsumura, H., and Izui, K. (2003). Phosphoenolpyruvate carboxylase: three-dimensional structure and molecular mechanisms. Arch. Biochem. Biophys. 414, 170-179.

Kalyuzhnaya, M. G., Korotkova, N., Crowther, G., Marx, C. J., Lidstrom, M. E., and Chistoserdova, L. (2005). Analysis of gene islands involved in methanopterin-linked C1 transfer reactions reveals new functions and provides evolutionary insights. J. Bacteriol. 187, 4607-4614.

Karsten, W. E., Ohshiro, T., Izumi, Y., and Cook, P. F. (2001). Initial velocity, spectral, and $\mathrm{pH}$ studies of the serine-glyoxylate aminotransferase from Hyphomicrobiuim methylovorum. Arch. Biochem. Biophys. 388, 267-275.
Kelly, D. P., Anthony, C., and Murrell, J. C. (2005). Insights into the obligate methanotroph Methylococcus capsulatus. Trends Microbiol. 13, 195-198.

Khadem, A. F., Pol, A., Wieczorek, A., Mohammadi, S. S., Francoijs, K. J., Stunnenberg, H. G., et al. (2011). Autotrophic methanotrophy in Verrucomicrobia: Methylacidiphilum fumariolicum SolV uses the Calvin-Benson-Bassham cycle for carbon dioxide fixation. J. Bacteriol. 193, 4438-4446.

Kim, H. J., and Graham, D. W. (2001). Effect of oxygen level on simultaneous nitrogenase and sMMO expression and activity in Methylosinus trichosporium OB3b and its sMMoC mutant, PP319: aerotolerant N2 fixation in PP319. FEMS Microbiol. Lett. 201, 133-138.

Kim, H. J., Graham, D. W., DiSpirito, A. A., Alterman, M. A., Galeva, N., Larive, C. K., et al. (2004). Methanobactin, a copperacquisition compound from methane-oxidizing bacteria. Science 305, 1612-1615.

Krentz, B. D., Mulheron, H. J., Semrau, J. D., Dispirito, A. A., Bandow, N. L., Haft, D. H., et al. (2010). A comparison of methanobactins from Methylosinus trichosporium OB3b and Methylocystis strain Sb2 predicts methanobactins are synthesized from diverse peptide precursors modified to create a common core for binding and reducing copper ions. Biochemistry 49, 10117-10130.

Large, P. J., and Quayle, J. R. (1963). Microbial growth on $\mathrm{C}(1)$ compounds. 5. Enzyme activities in extracts of Pseudomonas AM1. Biochem. J. 87, 386-396.

Larkin, M. A., Blackshields, G., Brown, N. P., Chenna, R., McGettigan, P. A., McWilliam, H., et al. (2007). Clustal W and Clustal X version 2.0. Bioinformatics 23, 2947-2948.

Lawrence, A. J., and Quayle, J. R. (1970). Alternative carbon assimilation pathways in methane-utilizing bacteria. J. Gen. Microbiol. 63, 371-374.

Letunic, I., and Bork, P. (2007). Interactive Tree Of Life (iTOL): an online tool for phylogenetic tree display and annotation. Bioinformatics 23, 127-128.

Li, H., and Durbin, R. (2009). Fast and accurate short read alignment with Burrows-Wheeler transform. Bioinformatics 25, 1754-1760.

Liepman, A. H., and Olsen, L. J. (2001). Peroxisomal alanine: glyoxylate aminotransferase (AGT1) is a photorespiratory enzyme with multiple substrates in Arabidopsis thaliana. Plant J. 25, 487-498.

Lloyd, J. S., Finch, R., Dalton, H. and Murrell, J. C. (1999). Homologous expression of soluble methane monooxygenase genes in Methylosinus trichosporium OB3b. Microbiology 145, 461-470.

Matsumura, H., Xie, Y., Shirakata, S., Inoue, T., Yoshinaga, T., Ueno, Y., et al. (2002). Crystal structures of C4 form maize and quaternary complex of E. coli phosphoenolpyruvate carboxylases. Structure 10, 1721-1730.

Mortazavi, A., Williams, B. A., McCue, K., Schaeffer, L., and Wold, B. (2008). Mapping and quantifying mammalian transcriptomes by RNA-Seq. Nat. Methods 5, 621-628.

Murrell, C. J., and Dalton, H. (1983a). Ammonia assimilation in Methylococcus capsulatus (Bath) and other obligate methanotrophs. Microbiology 129, 1197-1206.

Murrell, J. C., and Dalton, H. (1983b). Purification and properties of glutamine synthetase from Methylococcus capsulatus (Bath). J. Gen. Microbiol. 129, 1187-1196.

Murrell, J. C., and Jetten, M. S. M. (2009). The microbial methane cycle. Environ. Microbiol. Rep. 1 , 279-284.

Murrell, J. C., McDonald, I. R., and Gilbert, B. (2000). Regulation of expression of methane monooxygenases by copper ions. Trends Microbiol. 8, 221-225.

Naguib, M. (1979). Alternative carboxylation reactions in type II methylotrophs and the localization of carboxylase activities in the intracytoplasmic membranes. Z. Allg. Mikrobio. 19, 333-342.

Newaz, S. S., and Hersh, L. B. (1975) Reduced nicotinamide adenine dinucleotide-activated phosphoenolpyruvate carboxylase in Pseudomonas MA: potential regulation between carbon assimilation and energy production. J. Bacteriol. 124, 825-833.

Nielsen, A. K., Gerdes, K., and Murrell, J. C. (1997). Copper-dependent reciprocal transcriptional regulation of methane monooxygenase genes in Methylococcus capsulatus and Methylosinus trichosporium. Mol. Microbiol. 25, 399-409.

Oakley, C. J., and Murrell, J. C. (1988). nifH genes in the obligate methane oxidizing bacteria. FEMS Micriobiol. Lett. 49, 53-57.

Oldenhuis, R., Oedzes, J. Y., van der Waarde, J. J., and Janssen, D. B. (1991). Kinetics of chlorinated hydrocarbon degradation by Methylosinus trichosporium $\mathrm{OB} 3 \mathrm{~b}$ and toxicity of trichloroethylene. Appl. Environ. Microbiol. 57, 7-14.

Park, S., Hanna, L. M., Taylor, R. T., and Droege, M. W. (1991). Batch cultivation of Methylosinus trichosporium OB3b. I: production of soluble methane monooxygenase. Biotechnol. Bioeng. 38, 423-433.

Park, S., Shah, N. N., Taylor, R. T., and Droege, M. W. (1992). Batch cultivation of Methylosinus trichosporium OB3b: II. production of particulate methane monooxygenase. Biotechnol. Bioeng. 40, 151-157.

Patel, R. N., Hoare, S. L., and Hoare, D. S. (1979). (14C) acetate assimilation by obligate methylotrophs, Pseudomonas methanica and Methylosinus trichosporium. Antonie Van Leeuwenhoek 45, 499-511.

Patel, R. N., Hou, C. T., Derelanko, P., and Felix, A. (1980). Purification and properties of a heme-containing aldehyde dehydrogenase from Methylosinus trichosporium. Arch. Biochem. Biophys. 203, 654-662.

Peyraud, R., Kiefer, P., Christen, P., Massou, S., Portais, J. C., and Vorholt, J. A. (2009). Demonstration of the ethylmalonyl-CoA pathway by using 13C metabolomics. Proc. Natl. Acad. Sci. U.S.A. 106, 4846-4851.

Phelps, P. A., Agarwal, S. K., Speitel, G. E. Jr., and Georgiou, G. (1992). Methylosinus trichosporium $\mathrm{OB} 3 \mathrm{~b}$ mutants having constitutive expression of soluble methane monooxygenase in the presence of high levels of copper. Appl. Environ. Microbiol. 58, 3701-3708.

Pieja, A. J., Sundstrom, E. R., and Criddle, C. S. (2011). Poly-3hydroxybutyrate metabolism in the type II methanotroph Methylocystis parvus OBBP. Appl. Environ. Microbiol. 77, 6012-6019.

Rasche, M. E., Havemann, S. A., and Rosenzvaig, M. (2004). Characterization of two methanopterin biosynthesis mutants of Methylobacterium extorquens AM1 by use of a tetrahydromethanopterin bioassay. J. Bacteriol. 5, 1565-1570.

Reshetnikov, A. S., Rozova, O. N., Khmelenina, V. N., Mustakhimov, I. I., Beschastny, A. P., Murrell, J. C., et al. (2008). Characterization of the pyrophosphate-dependent 6 phosphofructokinase from Methylococcus capsulatus Bath. FEMS Microbiol. Lett. 288, 202-210.

Rozova, O. N., Khmelenina, V. N., and Trotsenko, Y. A. (2012). Characterization of recombinant $\mathrm{PPi}$ dependent 6-phosphofructokinases 
from Methylosinus trichosporium OB3b and Methylobacterium nodulans ORS 2060. Biochemistry Mosc. 77, 288-295.

Schmidt, S., Christen, P., Kiefer, P., and Vorholt, J. A. (2010). Functional investigation of methanol dehydrogenase-like protein XoxF in Methylobacterium extorquens AM1. Microbiology 156, 2575-2586.

Schulz, M. H., Zerbino, D. R., Vingron, M., and Birney, E. (2012). Oases: robust de novo RNA-seq assembly across the dynamic range of expression levels. Bioinformatics 28, 1086-1092.

Schwartz, A. C., Gockel, G., Gross, J., Moritz, B., and Meyer, H. E. (2004). Relations and functions of dyelinked formaldehyde dehydrogenase from Hyphomicrobium zavarzinii revealed by sequence determination and analysis. Arch. Microbiol. 182, 458-466.

Semrau, J. D., DiSpirito, A. A., and Yoon, S. (2010). Methanotrophs and copper. FEMS Microbiol. Rev. 34, 496-531.

Shishkina, V. N., and Trotsenko, Y. A. (1979). Pathways of ammonia assimilation in obligate methane utilizers. FEMS Microbiol. Lett. 5, 187-191.

Shishkina, V. N., and Trotsenko, Y. A. (1982). Multiple enzymatic lesions in obligate methanotrophic bacteria. FEMS Microbiol. Lett. 13, 237-242.

Skovran, E., Palmer, A. D., Rountree, A. M., Good, N. M., and Lidstrom, M. E. (2011). XoxF is required for expression of methanol dehydrogenase in Methylobacterium extorquens AM1. J. Bacteriol. 193, 6032-6038.

Stein, L. Y., Bringel, F., DiSpirito, A. A., Han, S., Jetten, M. S., Kalyuzhnaya, M. G., et al. (2011). Genome sequence of the methanotrophic alphaproteobacterium Methylocystis sp. strain Rockwell (ATCC 49242). J. Bacteriol. 193, 2668-2669.

Stein, L. Y., Yoon, S., Semrau, J. D., Dispirito, A. A., Crombie, A., Murrell, J. C., et al. (2010). Genome sequence of the obligate methanotroph Methylosinus trichosporium strain OB3b. J. Bacteriol. 192, 6497-6498.

Stolyar, S., Costello, A. M., Peeples, T. L., and Lidstrom, M. E. (1999). Role of multiple gene copies in particulate methane monooxygenase activity in the methane-oxidizing bacterium Methylococcus capsulatus Bath. Microbiology 145, 1235-1244.

Strom, T., Ference, T., and Quayle, J. R. (1974). The carbon assimilation pathways of Methylococcus capsulatus, Pseudomonas methanica, and Methylosinus trichosporium (OB3B) during growth on methane. Biochemistry 144, 465-476.

Takahashi, R., Ohmori, T., Watanabe, K., and Tokuyama, T. (1993). Phosphoenolpyruvate carboxylase of an ammonia-oxidizing chemoautotrophic bacterium, Nitrosomonas europaea ATCC 25978. J. Ferment. Bioeng. 76, 232-234.

Toyama, H., Chistoserdova, L., and Lidstrom, M. E. (1997). Sequence analysis of pqq genes required for biosynthesis of pyrroloquinoline quinone in Methylobacterium extorquens $\mathrm{AM} 1$ and the purification of a biosynthetic intermediate. Microbiology 143, 595-602.

Trotsenko, Y. A. (1976). "Isolation and characterization of obligate methanotrophic bacteria," in Microbial Production and Utilization of Gases, eds H. G. Schlegel, G. Gottschalk, and N. Pfennig (Gottingen: Goltze), 329-336.

Trotsenko, Y. A., and Murrell, J. C. (2008). Metabolic aspects of aerobic obligate methanotrophy. Adv. Appl. Microbiol. 63, 183-229.

Vallenet, D., Labarre, L., Rouy, Z., Barbe, V., Bocs, S., Cruveiller, S., et al. (2006). MaGe: a microbial genome annotation system supported by synteny results. Nucleic Acids Res. 10, 53-65.

Vorholt, J. A., Chistoserdova, L., Stolyar, S. M., Thauer, R. K., and
Lidstrom, M. E. (1999). Distribution of tetrahydromethanopterindependent enzymes in methylotrophic bacteria and phylogeny of methenyl tetrahydromethanopterin cyclohydrolases. J. Bacteriol. 181, 5750-5757.

Vorholt, J. A., Marx, C. J., Lidstrom, M. E., and Thauer, R. K. (2000). Novel formaldehyde-activating enzyme in Methylobacterium extorquens AM1 required for growth on methanol. $J$. Bacteriol. 182, 6645-6650.

Wadzink, A. M., and Ribbons, D. W. (1975). Utilization of acetate by Methanomonas methanooxidans. J. Bacteriol. 123, 380-381.

Ward, N., Larsen, O., Sakwa, J., Bruseth, L., Khouri, H., Durkin, A. S., et al. (2004). Genomic insights into methanotrophy: the complete genome sequence of Methylococcus capsulatus (Bath). PLoS Biol. 2:e303. doi:10.1371/journal.pbio.0020303

Weaver, T. L., Patrick, M. A., and Dugan, P. R. (1975). Whole-cell and membrane lipids o the methanotrophic bacterium Methylosinus trichosporium. J. Bacteriol. 124, 602-605.

Whittenbury, R., Phillips, K. C., and Wilkinson, J. F. (1970). Enrichment, isolation and some properties of methane-utilizing bacteria. J. Gen Microbiol. 61, 205-218.

Williams, A. M. (1988). The Biochemistry and Physiology of Polybeta-Hydroxybutyrate Metabolism in Methylosinus trichosporium OB3b. Ph.D. thesis, Biotechnology Centre, Cranfield Institute of Technology, Cranfield.

Wilson, S. M., Gleisten, M. P., and Donohue, T. J. (2008). Identification of proteins involved in formaldehyde metabolism by Rhodobacter sphaeroides. Microbiology 154 296-305.

Yamada, K., Shimoda, M., and Okura, I. (1991). Purification and characterization of methanol dehydrogenase from Methylosinus trichosporium (OB3b). J. Mol. Catal. 73 , 381-386.
Yang, S., Matsen, J. B., Konopka, M., Green-Saxena, A., Clubb, J., Sadilek, M., et al. (2013). Global molecular analyses of methane metabolism in methanotrophic Alphaproteobacterium, Methylosinus trichosporium OB3b. Part II. Metabolomics and 13C-labeling study. Front. Microbiol. 4:70 doi:10.3389/fmicb. 2013.00070

Yoon, S., Kraemer, S. M., DiSpirito, A. A., and Semrau, J. D. (2010). An assay for screen microbial cultures for chalkophore production. Environ. Microbiol. 2, 295-303.

Zerbino, D. R., and Birney, E. (2008). Velvet: algorithms for de novo short read assembly using de Bruijn graphs. Genome Res. 18, 821-829.

Conflict of Interest Statement: The authors declare that the research was conducted in the absence of any commercial or financial relationships that could be construed as a potential conflict of interest.

Received: 01 January 2013; paper pending published: 28 January 2013; accepted: 17 February 2013; published online: 03 April 2013

Citation: Matsen JB, Yang S, Stein $L Y$, Beck $D$ and Kalyuzhnaya MG (2013) Global molecular analyses of methane metabolism in methanotrophic alphaproteobacterium, Methylosinus trichosporium OB3b. Part I: transcriptomic study. Front. Microbiol. 4:40. doi:10.3389/fmicb.2013.00040

This article was submitted to Frontiers in Microbiological Chemistry, a specialty of Frontiers in Microbiology.

Copyright (c) 2013 Matsen, Yang, Stein, Beck and Kalyuzhnaya. This is an openaccess article distributed under the terms of the Creative Commons Attribution License, which permits use, distribution and reproduction in other forums, provided the original authors and source are credited and subject to any copyright notices concerning any third-party graphics etc. 